\title{
Reversible retinal vessel closure from VEGF-induced leukocyte plugging
}

\author{
Yuanyuan Liu, ${ }^{1,2}$ Jikui Shen, ${ }^{1,2}$ Seth D. Fortmann, ${ }^{1,2}$ Jiangxia Wang, ${ }^{3}$ Dietmar Vestweber, ${ }^{4}$ \\ and Peter A. Campochiaro ${ }^{1,2}$ \\ 'Department of Ophthalmology and ${ }^{2}$ Department of Neuroscience, Johns Hopkins University School of Medicine, \\ Baltimore, Maryland, USA. ${ }^{3} J o h n s$ Hopkins Biostatistics Center, Johns Hopkins Bloomberg School of Public Health, \\ Baltimore, Maryland, USA. ${ }^{4}$ Department of Cell Biology, Max-Planck-Institute of Molecular Biomedicine, \\ Muenster, Germany.
}

Clinical trials in patients with macular edema due to diabetic retinopathy or retinal vein occlusion (RVO) have shown that suppression of VEGF not only improves macular edema, but also reopens closed retinal vessels, prevents progression of vessel closure, and improves retinopathy. In this study, we show the molecular basis for those clinical observations. Increased retinal levels of VEGF in mice cause plugging of retinal vessels with leukocytes, vessel closure, and hypoxia. Suppression of VEGF reduces leukocyte plugging, causing reperfusion of closed vessels. Activation of VEGFR1 contributes to leukocyte recruitment, because it is significantly reduced by an anti-VEGFR1neutralizing antibody. High VEGF increases transcriptional activity of NF- $\mathrm{KB}$ and expression of NF- $\mathrm{B}$ target genes, particularly Vcam1. Injection of an anti-VCAM-1-neutralizing antibody reduces VEGF-induced leukocyte plugging. These data explain the broad range of benefits obtained by VEGF suppression in patients with ischemic retinopathies, provide an important insight into the pathogenesis of RVO and diabetic retinopathy, and suggest that sustained suppression of VECF early in the course of these diseases may prevent vessel closure, worsening ischemia, and disease progression. This study also identifies VEGFR1 and VCAM-1 as molecular targets whose suppression could supplement VEGF neutralization for treatment of RVO and diabetic retinopathy.

Conflict of interest: The authors have declared that no conflict of interest exists.

Submitted: June 7, 2017

Accepted: August 8, 2017

Published: September 21, 2017

Reference information:

JCI Insight. 2017;2(18):e95530.

https://doi.org/10.1172/jci.

insight. 95530.

\section{Introduction}

Diabetic retinopathy is a major complication of diabetes that is a highly prevalent cause of moderate and severe vision loss (1). The Diabetes Control and Complication Trial and the United Kingdom Prospective Diabetes Study demonstrated that hyperglycemia is a key driver of diabetic retinopathy because tight control of blood glucose provides substantial benefit $(2,3)$. Glucose enters the retina primarily through facilitative transport, and therefore, high blood glucose leads to high glucose in the retina, which, after many years, leads to the classic signs of diabetic retinopathy: retinal hemorrhages, microaneurysms, and cotton wool spots (microinfarcts). Patients are usually asymptomatic when these first signs of diabetic retinopathy appear, and it may be several years before decreased vision occurs from progression to more advanced stages of diabetic retinopathy, diabetic macular edema (DME), or proliferative diabetic retinopathy (PDR) (4). There are many hypotheses with supporting data as to how high retinal glucose leads to vascular damage and ultimately to DME and/or PDR, including production of advanced glycation end products (5), oxidative stress (6-8), increased cytokine expression and inflammation (9), or neuronal damage and neurovascular crosstalk (10), but conclusive proof for any of the competing hypotheses has been elusive. The long latent period between the onset of hyperglycemia and clinical signs of diabetic retinopathy and the variable and often long period between the onset of signs and the development of DME or PDR have prevented development of an animal model that closely mimics diabetic retinopathy (11); this has made it difficult to determine whether the hyperglycemia-induced abnormalities listed above contribute to the development of late vascular changes seen in human diabetic retinas.

The most consequential vascular change in diabetic retinopathy is retinal vessel closure resulting in areas of retinal nonperfusion and ischemia, because nonperfusion correlates with diabetic retinopathy severity and the development of $\operatorname{PDR}(12,13)$. Retinal nonperfusion also occurs in other retinal diseases, and, along with diabetic retinopathy, they are classified as ischemic retinopathies. The second most preva- 
lent ischemic retinopathy is retinal vein occlusion (RVO) (14). Central RVO (CRVO) affects the entire retina, while occlusion of a branch of the central retinal vein, branch RVO (BRVO), affects $50 \%$ or less of the retina. Since a larger area of the retina is affected by CRVO than BRVO, on average there is greater retinal ischemia and more severe pathology in patients with CRVO.

While rodents with diabetes may develop microscopic evidence of vessel closure manifested by acellular capillaries, retinal nonperfusion visualized by fluorescein angiography like that seen in patients with diabetic retinopathy is not observed and PDR does not occur (11). In fact, PDR and DME do not occur in any diabetic animals, even nonhuman primates. It is possible to model RVO by damaging veins with laser photocoagulation, which results in obstruction, retinal ischemia, and retinal neovascularization (NV) (15). High inspired oxygen during retinal vascular development in laboratory animals results in large areas of retinal nonperfusion and retinal NV; this model is referred to as oxygen-induced ischemic retinopathy (16, 17). Oxygen-induced ischemic retinopathy and laser-induced RVO helped to establish the link between increased expression of VEGF in ischemic retina and the development of retinal NV $(18,19)$. Clinical observations and later clinical trials confirmed the critical role of VEGF in PDR, because VEGF-neutralizing proteins cause regression of retinal NV $(20,21)$. Since DME does not occur in animals, pathogenesis was investigated in small clinical trials. Treatment with continuous high inspired oxygen resulted in improvement in DME, implicating retinal hypoxia in the pathogenesis (22). Nonspecific or specific VEGF antagonists resulted in dramatic improvements in DME, demonstrating that VEGF is a critical stimulator of DME $(23,24)$. The benefit of VEGF antagonists in DME was confirmed in large multicenter clinical trials and they are now standard care $(25,26)$. Similarly, a small clinical trial demonstrated dramatic benefit in subjects with macular edema due to CRVO or BRVO (27), which was confirmed in phase 3 trials, and anti-VEGF agents are standard care for macular edema due to RVO $(28,29)$.

The use of VEGF-neutralizing proteins in patients with DME or macular edema due to RVO have provided other unexpected insights into pathogenesis. Measurement of retinal nonperfusion in clinical trials have shown that progression of retinal nonperfusion is extremely common in untreated patients with CRVO or BRVO $(30,31)$. Suppression of VEGF slowed progression of retinal nonperfusion and caused reopening of some previously closed retinal vessels in patients with CRVO or BRVO, whereas sham-treated patients or those in whom anti-VEGF treatment was stopped had progressive worsening of retinal nonperfusion (32-34). Some patients have nonperfusion that does not improve with VEGF suppression, and patients who show improvement in one region of nonperfusion may not in another, indicating that a substantial amount of nonperfusion is permanent, though the demonstration that some is reversible was surprising and exciting. Similar observations were made in patients with DME over a more prolonged period of time (35). These studies showed that high levels of VEGF cause closure of retinal vessels, which for a period of time can be reopened by VEGF suppression, but, without treatment or by suspending treatment, permanent closure and retinal nonperfusion occur. Suppression of VEGF also resulted in improvements in background diabetic retinopathy (36). Thus, VEGF plays a larger role in the pathogenesis of ischemic retinopathies than previously expected, but the mechanism by which it promotes reversible vessel closure is unknown. In this study, we sought to answer that question.

\section{Results}

Intraocular injection of VEGF causes transient leukostasis. Twenty-four hours after intravitreous injection of 1 $\mu \mathrm{gEGF}_{165}$ (VEGF) or PBS in one eye, adult C57BL/6 mice were perfused through the left ventricle with rhodamine-conjugated concanavalin A (Con A). Compared with PBS-injected eyes in which fluorescence microscopy of retinal flat mounts showed narrow vessels that rarely contained leukocytes (Figure 1A), VEGF-injected eyes showed dilated retinal vessels, a well-establish effect of VEGF due to stimulation of eNOS (37-39), containing clumps of leukocytes adherent to the endothelium (Figure 1B). There was a marked decrease in leukocytes within retinal vessels at 48 hours after VEGF injection, but, 72 hours after injection, many leukocytes were again seen within large retinal vessels (Figure 1, C and D). At 96 hours after VEGF injection, there were few leukocytes in retinal vessels. Perfusion with fluorescein-labeled dextran 24 hours after injection showed the normal appearance of retinal vessels in PBS-injected eyes (Figure 1E), but eyes injected with VEGF had dilated vessels, with many leukocytes seen in negative relief (Figure $1 \mathrm{~F}$, arrowheads). Compared with fluorescein angiograms in PBS-injected eyes (Figure 1G), those done 24 hours after injection of $1 \mu \mathrm{g}$ VEGF had dilated vessels, which combined with leakage and staining of vessel walls caused small vessels to stand out (Figure $1 \mathrm{H}$ ). No perfusion defects were seen. Quantification of the mean 

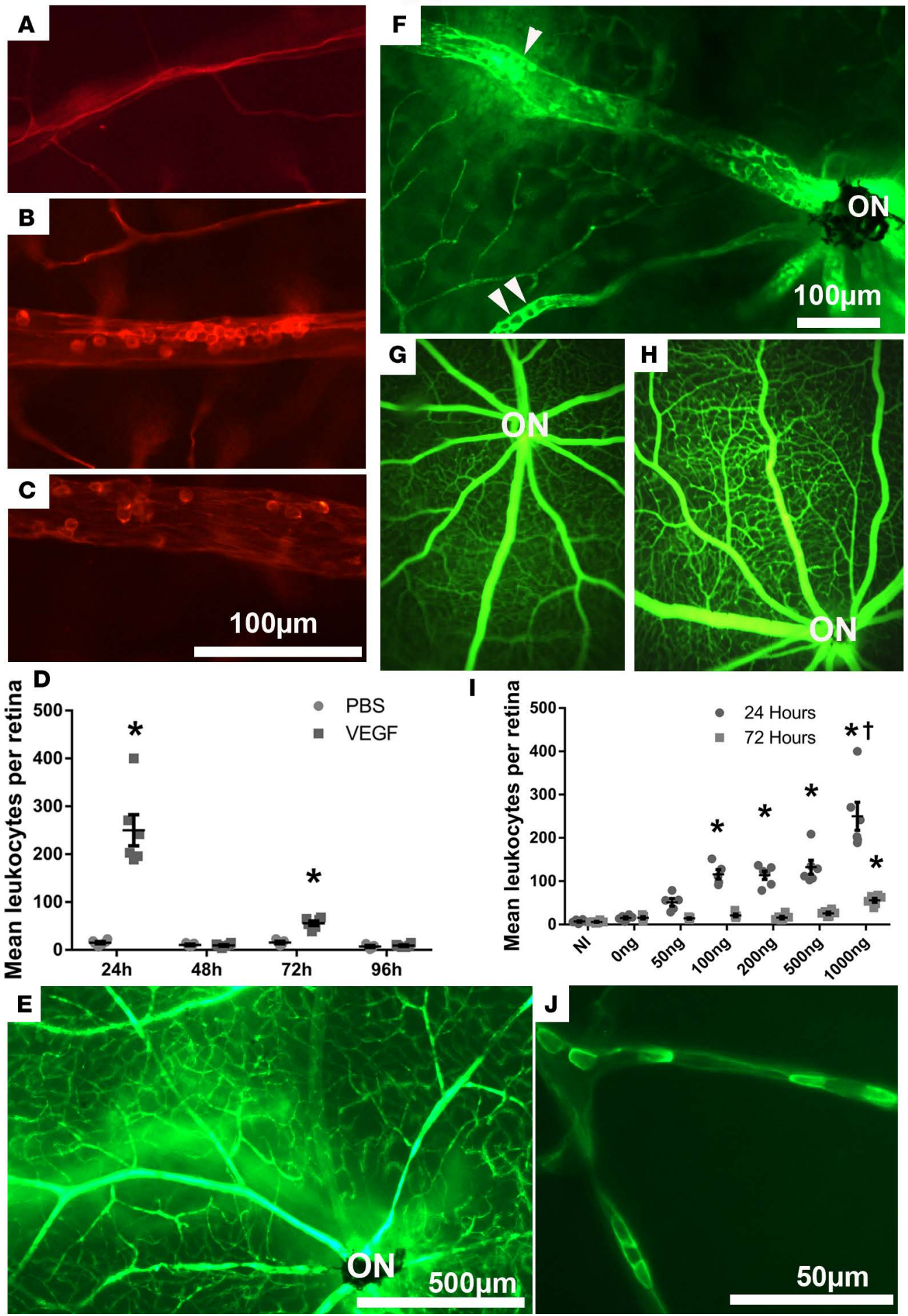

Figure 1. Intravitreous injection of VEGF causes transient severe leukostasis in retinal vessels. Retinal vessels in mice perfused with rhodamine-labeled concanavalin A (con A) were narrow and most did not contain any leukocytes 24 hours after intravitreous injection of PBS (A) but were dilated and packed with leukocytes 24 hours (B) or 72 hours (C) after intravitreous injection of $1 \mu \mathrm{g}$ VEGF. The mean ( \pm SEM) number of intravascular leukocytes per retina (PBS-treated mice, $n=5$; VEGF-treated mice, $n=6$ at each time point) was significantly greater in VEGF-injected eyes compared with PBS-injected eyes at 24 and 72 hours after injection $\left({ }^{*} P<0.001\right.$ by unpaired $t$ tests) but not at 48 or 96 hours (D, $P=0.6179$ [ 48 hours], $P=0.4722$ [96 hours] by unpaired $t$ tests). Retinal vessels in a region around the optic nerve (ON) of mice perfused with fluorescein-labeled dextran showed normal retinal vasculature 24 hours after intravitreous injection of PBS (E), whereas vessels were dilated and packed with leukocytes seen in negative relief 24 hours after injection of $1 \mu \mathrm{g}$ VEGF (F, arrowheads). Fluorescein angiography 24 hours after injection of PBS (G) or 1 $\mu \mathrm{g}$ VEGF (H) showed no identifiable nonperfusion. (I) The mean ( \pm SEM) number of intravascular leukocytes per retina ( $N I$ group $n=6$, mice treated with $200 \mathrm{ng}, 500 \mathrm{ng}, 1,000 \mathrm{ng}$ VEGF $n=6$; mice treated with $0 \mathrm{ng}, 50 \mathrm{ng}, 100 \mathrm{ng}$ VEGF $n=5$ ) was determined for several doses of VEGF and was significantly greater than PBS control for doses $\geq 100 \mathrm{ng}\left({ }^{*} P \leq 0.002,{ }^{\dagger} P<0.001 ; P=0.002\right.$ [100 ng, 24 hours], $P=0.001[200 \mathrm{ng}, 24$ hours], $P<0.001$ 
[500 ng, 24 hours], $P<0.001$ [1,000 ng, 24 hours and 72 hours] by 1-way ANOVA with Bonferroni correction for multiple comparisons). (J) Twenty-four hours after intravitreous injection of $200 \mathrm{ng}$ VEGF, perfusion with fluorescein-labeled Con A showed relatively small retinal vessels plugged with leukocytes. Scale bar: $50 \mu \mathrm{m}(\mathrm{J}) ; 100 \mu \mathrm{m}$ (A-C and F); $500 \mu \mathrm{m}$ (E).

number of intravascular leukocytes per retina after injection of various doses of VEGF showed a significant increase compared with PBS-injected eyes at 24 hours after injection of doses $\geq 100 \mathrm{ng}$ (Figure 1I). There were also significantly more leukocytes in retinal vessels 72 hours after injection of $1 \mu \mathrm{g}$ VEGF but not any of the lower doses. Compared with eyes injected with $1 \mu \mathrm{g}$ VEGF, those injected with lower doses appeared to have fewer leukocytes in large vessels and more leukocytes adherent in smaller vessels (Figure 1J).

Sustained increased expression of VEGF causes sustained leukostasis, reduced perfusion, and retinal hypoxia. Intravitreous injection of VEGF results in a sudden increase and then a fairly rapid decrease in retinal VEGF, which differs from the situation in eyes with ischemic retinopathy, in which there is sustained expression of VEGF in ischemic retina. Mice with doxycycline-inducible expression of VEGF in photoreceptors (Tet/ opsin/VEGF mice) have sustained expression of VEGF during treatment with doxycycline (40). One (Figure 2A) and two days (Figure 2B) after initiation of $2 \mathrm{mg} / \mathrm{ml}$ doxycycline in drinking water, many more leukocytes were adherent to the walls of small retinal vessels compared with those in PBS-injected eyes (Figure 1A) or uninjected eyes. Three days after the onset of doxycycline treatment, leukocytes were seen in vessels of all sizes, with large aggregates in large vessels (Figure 2, C and D). The mean number of intravascular leukocytes per retina was significantly greater 1, 2, and 3 days after starting doxycycline, compared with retinas of control mice not treated with doxycycline, and was significantly greater on day 3 compared with days 1 and 2 (Figure 2E). Fluorescein angiography 3 days after starting doxycycline showed dilated large retinal vessels radiating from the optic nerve. Between the large vessels, the network of small vessels was somewhat blurred by extravascular fluorescein leakage, punctuated by regions of hypofluorescence (Figure 2F, box). Magnification of the boxed area in Figure 2F shows patches of hypofluorescence, with sharp borders appearing cut out of the diffuse continuous fluorescence caused by retinal capillaries (Figure $2 \mathrm{G}$, asterisks). This is very similar in appearance to sharply cut out black areas on human fluorescein angiograms recognized as capillary closure (32). Retinas from Con A-perfused doxycycline-treated Tet/opsin/ $V E G F$ mice that were also stained with pimonidazole, a stain for hypoxic tissue, showed regions of retinal hypoxia adjacent to vessels containing leukocytes (Figure 2H). Retinas from Tet/opsin/VEGF mice that were not treated with doxycycline showed no pimonidazole staining (Supplemental Figure 1, A, C, and E; supplemental material available online with this article; https://doi.org/10.1172/jci.insight.95530DS1). A low-magnification image of a retina from a Con A-perfused doxycycline-treated Tet/opsin/VEGF mouse (Supplemental Figure 1, B, D, and F), in which leukocytes in retinal vessels are small but still discernible (Supplemental Figure 1B, box, and Supplemental Figure 1F, arrows), provides more perspective and shows that the hypoxia is not uniform throughout the retina, but rather occurs in patches.

Turning off VEGF expression or injection of a VEGF-neutralizing protein reduces leukostasis and opens closed vessels. On day 3 after intraperitoneal injections of doxycycline on days 0,1 , and 2 , retinal flat mounts from rhodamine-labeled Con A-perfused Tet/opsin/VEGF mice showed leukocytes adherent to the walls of retinal vessels (Figure 3A) that appeared to plug the lumen of some vessels (Figure 3B). On day 17, 2 weeks after the third injection of doxycycline, few intravascular leukocytes were seen (Figure 3C). Quantification of the number of intravascular leukocytes showed significantly more on day 3 when VEGF expression was high, compared with day 17 when VEGF levels had been normal for at least a week, indicating that most of the leukocytes had cleared (Figure 3D). Fluorescein angiograms obtained on day 3 showed dilation of large retinal vessels and severe extravascular leakage, resulting in diffuse hyperfluorescence filling spaces between small vessels; despite the increased overall fluorescence as a result of extravascular leakage, dark areas of retinal nonperfusion were seen (Figure 3E, boxes). A repeat fluorescein angiogram in the same Tet/opsin/ $V E G F$ mouse on day 17 showed that the large retinal vessels were no longer dilated, leakage had resolved allowing better resolution of small vessels; the previously black areas were filled in with a continuous network of vessels, indicating reopening of previously closed vessels (Figure 3F). Magnified images of the large boxed areas in Figure 3, E and F, allow better comparison of retinal vessels exposed to high levels of VEGF (Figure 3G) and the same vessels after reduction in VEGF levels (Figure 3H). High VEGF levels resulted in dilated large vessels with black patches between them indicating regions of vessel closure (Figure 3G, asterisks), while after levels of VEGF returned to normal, the same region of retina showed well-perfused vessels in the area where there previously were no vessels, indicating reopening of previously closed vessels 

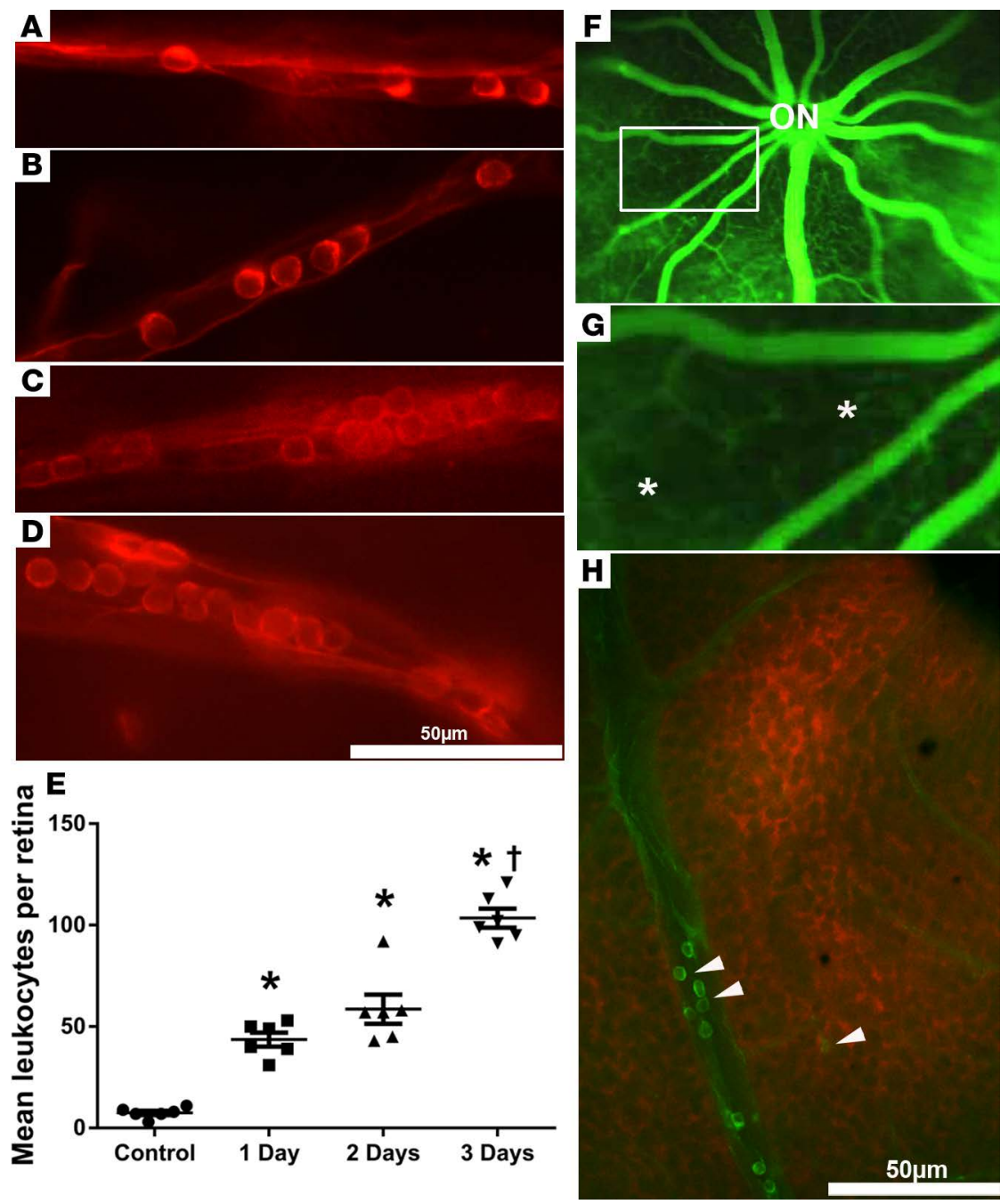

Figure 2. Sustained expression of VEGF in the retina causes leukostasis, retinal vessel closure, and retinal hypoxia. Tet/opsin/VEGF double-transgenic mice with doxycycline-inducible expression of VEGF in the retina were given $2 \mathrm{mg} / \mathrm{ml}$ doxycycline in drinking water and perfused with rhodamine-labeled Con $\mathbf{A} 1$ day (A), 2 days (B), or 3 days (C and D) after initiating doxycycline. Leukocytes were present in small vessels 1 day (A) and 2 days (B) after onset of VEGF expression and were present in vessels of all sizes after 3 days ( $C$ and $\mathbf{D})$. The mean ( \pm SEM) number of intravascular leukocytes per retina was significantly greater at each of the 3 time points compared with control (E) $\left({ }^{*} P<0.001\right.$ by 1-way ANOVA with Bonferroni corrections) and at day 3 was greater than other time points $\left({ }^{\dagger} P<\right.$ 0.01, 1-way ANOVA with Bonferroni corrections). (F) Fluorescein angiography of Tet/opsin/VEGF mice 3 days after starting doxycycline showed dilated large retinal vessels radiating from the optic nerve (ON), between which the networks of small vessels were slightly blurred by extravascular leakage. There were hypofluorescent areas with sharp borders that appeared cut out of the diffuse fluorescence (box), better seen in a magnified view of the boxed area (G, asterisks). The dark black areas indicate absence of capillaries due to nonperfusion. Staining of a retinal flat mount with hydroxyprobe 3 days after starting doxycycline showed hypoxic retina (red) adjacent to vessels containing adherent FITC-Con A-stained leukocytes (H, arrowheads). Scale bar: $50 \mu \mathrm{m}$.

(Figure 3H). Compared with Tet/opsin/VEGF mice given an intravitreous injection of PBS at the same time that doxycycline was started and hence at the onset of VEGF expression (Figure 3I), those given an injection of the VEGF-neutralizing protein aflibercept had significantly fewer intravascular leukocytes 3 days after starting doxycycline (Figure 3, J and K). Additionally, while areas of retinal nonperfusion were seen in PBS-injected eyes (Figure 3L, box, asterisks), they were not seen in aflibercept-injected eyes (Figure 3M). The magnified view of the boxed area in Figure 3L shows the black regions lacking perfused blood vessels in control eyes (Figure 3N, asterisks), while high-magnification images of retinas of aflibercept-treated eyes show a normal vascular pattern with no evidence of nonperfusion (Figure 3O).

Chronic elevation of VEGF expression results in gradually increasing leukostasis and retinal nonperfusion. In rho/ $V E G F$-transgenic mice, the rhodopsin promoter drives expression of VEGF, resulting in sustained expression in photoreceptors beginning 7 days after birth (41), but the steady-state retinal levels of VEGF are more than 30-fold lower than those in Tet/opsin/VEGF mice treated with $2 \mathrm{mg} / \mathrm{ml}$ doxycycline in drinking water (40). In 20- and 30-day-old rho/VEGF mice, several isolated intravascular leukocytes were seen (Figure 4, A and B). In 7-month-old or older rho/VEGF mice, there were many more intravascular leukocytes, and they often appeared to occlude the lumen of vessels, as seen in 3 separate 7-month-old mice in which there was plugging at a vessel bifurcation (Figure 4C), by a line of leukocytes in a relatively small vessel (Figure 4D), or packing of a substantial length of a vessel lumen with large aggregates (Figure 4E). Similarly, there were leukocytes plugging vessels particularly at branch points in the retinas of 12- and 15-month-old rho/VEGF mice (Figure 4, F and G). The mean $( \pm$ SEM) number of intravascular leukocytes per retina in 20- and 30-day-old rho/VEGF mice, but not those that were 16 days old, was significantly greater than that in normal 5 -week-old control mice, and the mean number of intravascular leukocytes was significantly greater in 7-, 12-, and 15-month-old rho/VEGF mice than 

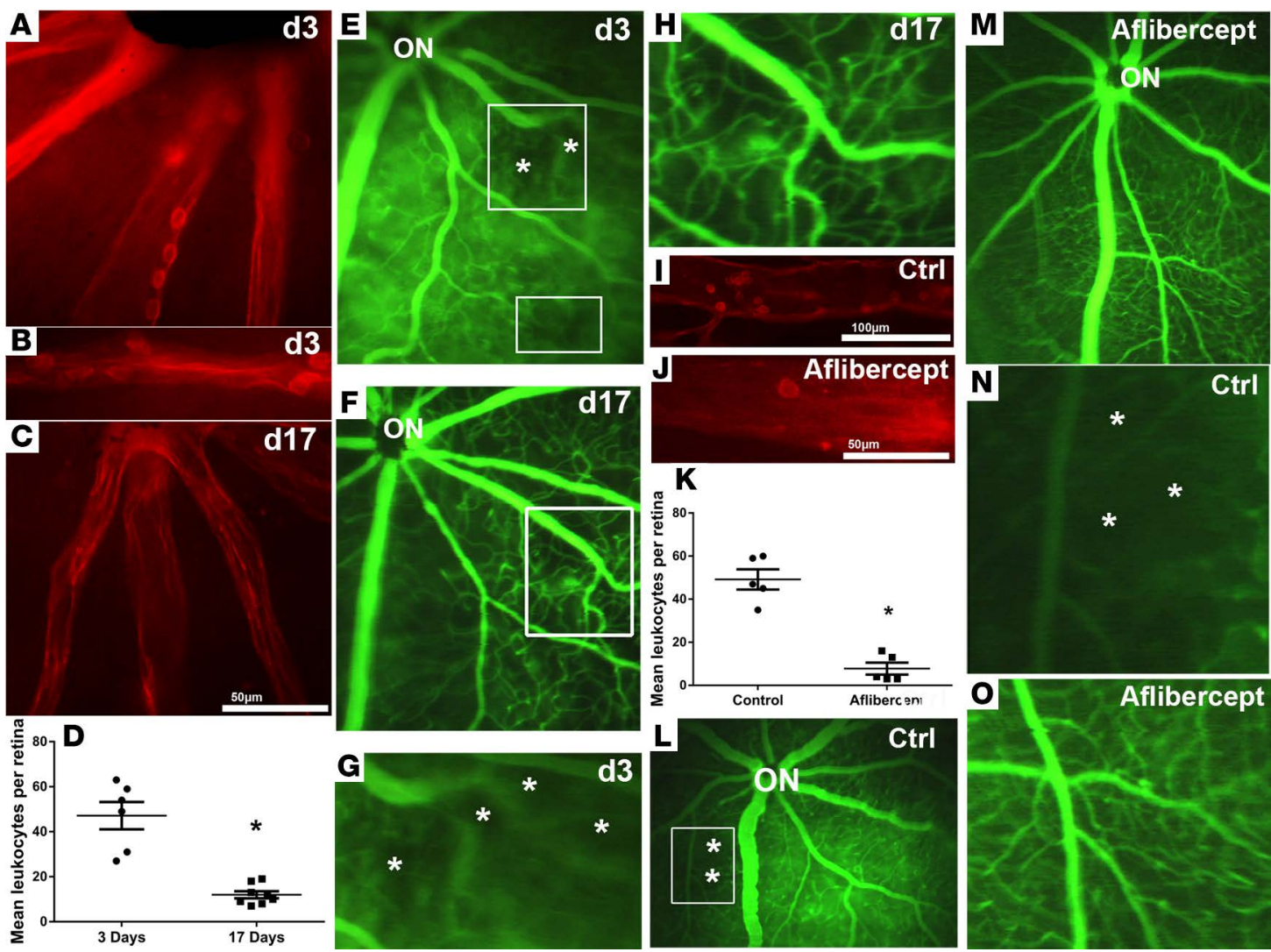

Figure 3. Turning off VEGF expression or injection of a VEGF-neutralizing protein reduces leukostasis and opens closed vessels. On day 3 after intraperitoneal injections of doxycycline on day $0(50 \mathrm{mg} / \mathrm{kg})$, day $1(25 \mathrm{mg} / \mathrm{kg})$, and day $2(25 \mathrm{mg} / \mathrm{kg})$, retinal flat mounts from rhodamine-labeled concanavalin A-perfused (Con A-perfused) Tet/opsin/VEGF mice showed leukocytes adherent to the walls of retinal vessels (A) that appeared to plug the lumen of some vessels (B). Other Tet/opsin/VEGF mice were given 3 injections of doxycycline and then maintained without treatment until day 17 when they were perfused with rhodamine-labeled Con A; retinal flat mounts showed few intravascular leukocytes (C). Tet/opsin/VEGF mice treated in the same manner were perfused with rhodamine-labeled Con A on day 3 or day $17(n=6, n=8)$, and the mean ( \pm SEM) number of intravascular leukocytes per retina was lower on day 17 than on day $3\left(\mathbf{D},{ }^{*} P<0.001\right.$ by unpaired $t$ test), indicating that most of the leukocytes had cleared. (E). Fluorescein angiograms obtained on day 3 showed dilation of large retinal vessels between which there was continuous fluorescence interrupted by hypofluorescent regions of nonperfusion (boxes, asterisks). (F). A repeat fluorescein angiogram in the same Tet/opsin/VECF mouse on day 17 showed that the large retinal vessels were no longer dilated, leakage had resolved allowing better resolution of small vessels, and the previously black areas were filled in with a continuous network of vessels, indicating reopening of previously closed vessels. Magnified images of the large boxed areas in $\mathbf{E}$ and $\mathbf{F}$ allowed a better visualization of regions of vessel closure induced by high expression of VEGF (G, asterisks), while the same region of retina showed reperfused vessels after levels of VEGF returned to normal (H).Tet/opsin/VEGF mice were given an intravitreous injection of $40 \mu \mathrm{g}$ aflibercept $(n=5)$ or PBS $(n=5)$, and $2 \mathrm{mg} / \mathrm{ml}$ doxycycline was added to their drinking water. After 3 days, control mice showed numerous intravascular leukocytes (I), while few leukocytes were seen in vessels of aflibercept-injected eyes $(\mathrm{J})$. The mean $\left( \pm\right.$ SEM) number of intravascular leukocytes was significantly lower in eyes injected with aflibercept $\left(\mathbf{K},{ }^{*} P<0.001 \mathrm{for}\right.$ difference from control by unpaired $t$ test). Fluorescein angiograms in control eyes showed dilation of large retinal vessels, diffuse hyperfluorescence from extravascular leakage, and areas of retinal nonperfusion (L, box), whereas eyes injected with aflibercept showed no vessel dilation, leakage, or retinal nonperfusion (M). Magnification of the boxed area in $\mathbf{L}$ clearly shows the dark black patches, indicating closure of retinal vessels in control mice (N, Ctrl, asterisks), while the magnified view of the retinal vessels in $\mathbf{M}$ shows the absence of any vessel closure in aflibercept-treated mice (0).

in 8-month-old normal control mice (Figure 4H). Fluorescein angiography in 7-month-old and 12-month-old rho/VEGF mice showed several areas of retinal nonperfusion (Figure 4I and Figure 4J, respectively, asterisks). In order to assess the effect of aflibercept, 7-month-old rho/VEGF mice had baseline fluorescein angiography on day 0 and then had subcutaneous injections of $25 \mathrm{mg} / \mathrm{kg}$ aflibercept on days $0,2,4$, and 6 and repeat fluorescein angiography on day 7 . There were many areas of retinal nonperfusion on the baseline fluorescein angiogram (Figure 5A) that were improved after treatment with aflibercept (Figure 5B). Even at low magnification, this was seen for the regions in the large and small boxes in which black regions surround asterisks in Figure 5A; the black areas are filled in with green, indicating reopening of vessels. Magnified images of the large boxed areas in Figure 5, A and B, demonstrate black regions devoid of vessels (Figure 5C, asterisks) that subsequently have perfused vessels (Figure 5D) but also show black areas (Figure 5C, dots), which remain black, indicating little or no reperfusion in those areas. 

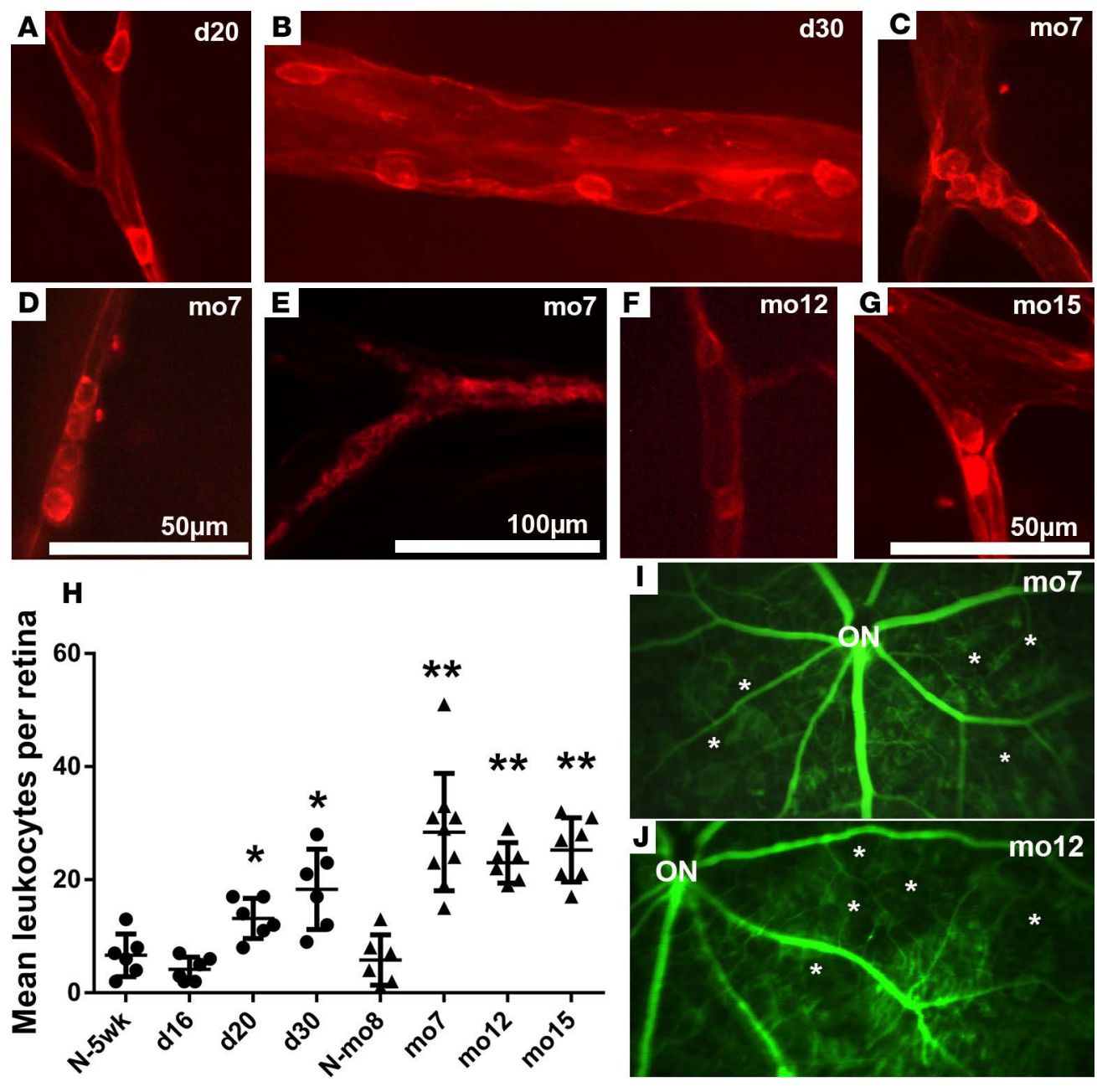

Figure 4. Chronic elevation of VEGF in the retinas of rho/VEGF-transgenic mice causes gradually increasing leukostasis and retinal nonperfusion. Rho/VEGF-transgenic mice of different ages, day 16, day 20, day 30, 7 months, 12 months, or 15 months, or normal wild-type mice at 5 weeks (N-5wk) or 8 months of age ( $\mathrm{N}$-mo8) were perfused with rhodamine-labeled Con A. Several vessels showed single adherent leukocytes in day 20 rho/VEGF mice (A) and more were seen in day 30 mice (B). In 7-month-old or older rho/VEGF mice, there were many more intravascular leukocytes and they often appeared to occlude the lumen of vessels exemplified in 3 separate 7-month-old mice by plugging at a vessel bifurcation (C), by a line of leukocytes (D), or packing of a substantial length of a vessel lumen with a large aggregate $(\mathbf{E})$. Similarly, there were leukocytes plugging vessels particularly at branch points in the retinas of 12-month-old (F) and 15-month-old (G) rho/VEGF mice. The mean ( \pm SEM) number of intravascular leukocytes per retina in both 20-day-old and 30-day-old $r$ ho/VEGF mice, but not 16-day-old mice, was significantly greater than that in N-5W control mice $\left({ }^{*} P=0.05 ; P=0.022\right.$ [day 20 ], $P<0.001$ [day 30], $P=0.349$ [day 16] compared to 5 weeks by unpaired $t$ tests) and mean intravascular leukocytes were significantly greater in 7-month-old, 12-monthold, and 15-month-old rho/VEGF mice compared with N-8M control mice $(\mathbf{H})\left(n=6\right.$ for each bar except 7 months, for which $n=9$; ${ }^{* *} P<0.001$ by unpaired $t$ tests). Retinal flat mounts from fluorescein-dextran-perfused 7-month-old (I) and 12-month-old (J) rho/VEGF mice show abruptly ending vessels and large areas of nonperfusion (asterisks). Scale bar: $50 \mu \mathrm{m}$ (A-D and $\mathbf{G}) ; 100 \mu \mathrm{m}$ (E and $\mathbf{F})$.

Stimulation of VEGFR1 contributes to leukocyte recruitment. VEGFR1 has been demonstrated on monocytes, macrophages, and neutrophils and mediates VEGF-stimulated leukocyte migration (42, 43). To determine if VEGFR1 on leukocytes contributes to VEGF-induced retinal leukostasis, mice were given an intravenous injection of $100 \mu \mathrm{g}$ rat anti-mouse VEGFR1 or rat IgG and an intraocular injection of $200 \mathrm{ng}$ VEGF, and, after 24 hours, they were perfused with FITC-labeled Con A. Compared with control IgG-injected mice (Figure 6A), there were significantly fewer intravascular leukocytes in retinal vessels of anti-VEGFR1-injected mice (Figure 6, B and C). Staining of retinal flat mounts from FITC-labeled Con A-perfused mice 24 hours after injection of $200 \mathrm{ng}$ VEGF with F4/80, which binds monocytes and macrophages (Figure 6, D-F), or anti-Ly6G, which binds neutrophils (Figure 6, G-I), showed that leukocytes of monocyte lineage and neutrophils participate in VEGF-induced retinal leukostasis. 

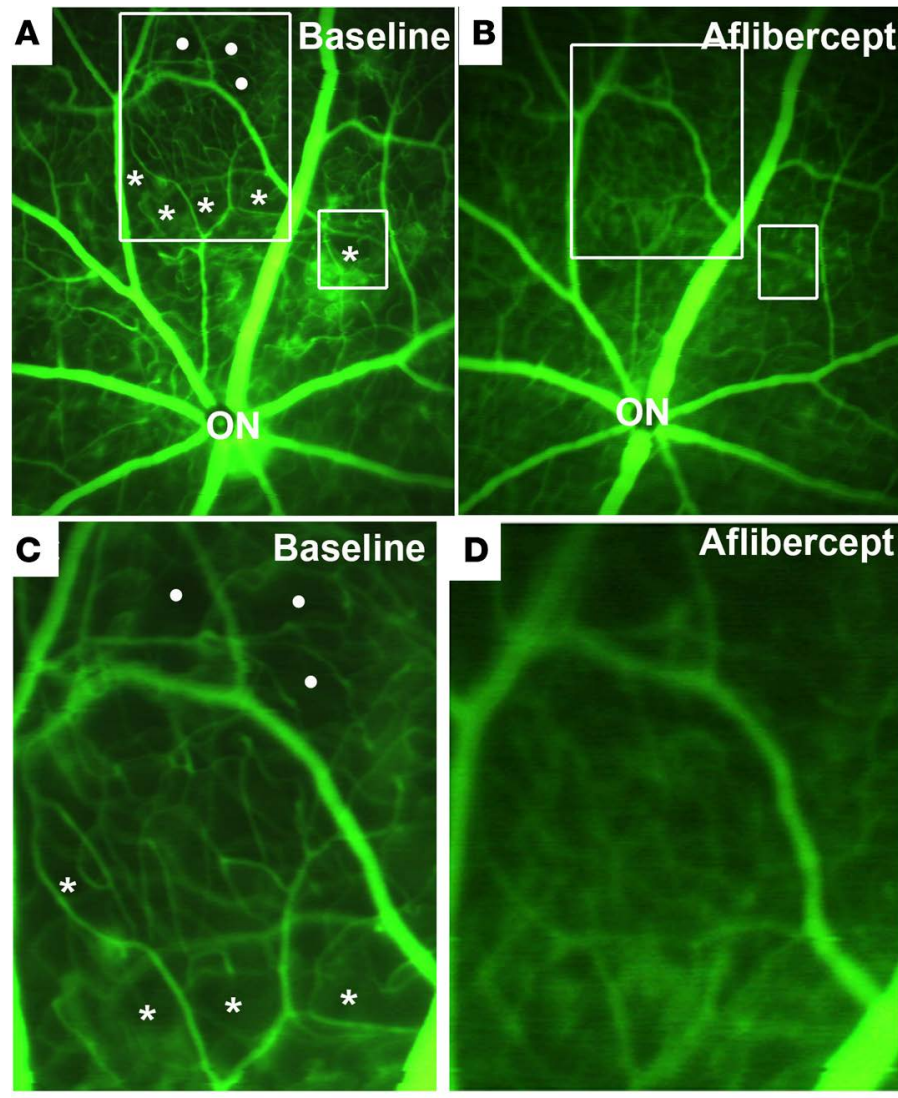

Figure 5. Intravitreous injection of a VEGF-neutralizing protein causes opening of some vessels closed by chronic overexpression of VEGF in the retinas of rho/VEGF mice. Fluorescein angiography (FA) was done on 7-month-old rho/VEGF mice (A), and then the mice were given subcutaneous injections of $25 \mathrm{mg} / \mathrm{kg}$ aflibercept every other day for a total of 4 injections followed by repeat FA (B). At baseline prior to aflibercept injection, several black areas devoid of fluorescein were seen, indicating closure of retinal vessels (A, asterisks and dots within boxes). After aflibercept injections, many of the nonperfused areas were perfused indicating opening of previously closed vessels (B, boxes). Comparison of a magnified view of the large white box in $\mathbf{A}(\mathbf{C})$ with a magnified view of box in $\mathbf{B}$, the same region of the retina after aflibercept treatment (D), shows 4 black regions devoid of blood vessels (C, asterisks) in which vessels reappear after aflibercept treatment indicating reopening (D). However, other black areas (dots) remain black after aflibercept treatment indicating that not all closed vessels reopen.

VEGF stimulates expression of mediators of leukocyte adhesion. The transcription factor $\mathrm{NF}-\kappa \mathrm{B}$ increases expression of many proteins involved in leukocyte-endothelial cell adhesion. To determine if VEGF activates NF- $\mathrm{\kappa B}$ in retinal vascular endothelial cells, primary human retinal endothelial cell cultures (HRECs) were incubated in $25 \mathrm{ng} / \mathrm{ml}$ VEGF for 0 , 1, or 2 hours, and $\mathrm{NF}-\kappa \mathrm{B}$ transcriptional activity was measured. There was a large increase in NF- $\mathrm{NB}$ transcriptional activity in HRECs exposed to VEGF for 1 hour that was decreased but still significantly higher than that of controls at 2 hours (Figure 7A). Expression of the NF- $\kappa \mathrm{B}$ target gene Vcam1 was dramatically increased in HRECs after exposure to VEGF for 4 hours (Figure 7B). The constitutive level of mRNA for ICAM-1 was quite high in HRECs, and exposure to VEGF caused a modest, statistically significant increase (Figure 7C). Exposure of HRECs to VEGF for 4 hours also caused a significant increase in mRNA for E selectin (Figure 7D) but not in mRNA for ICAM-2, P selectin, or vascular adhesion protein (VAP; Supplemental Figure 2, A-C). There was little immunostaining for VCAM-1 in HRECs that were not exposed to VEGF (Figure 7, E and G), but those exposed to VEGF for 4 hours showed strong staining for VCAM-1 (Figure 7, F and $\mathrm{H}$ ).

We sought to determine if the effects of VEGF on cultured endothelial cells predicted effects on retinal endothelial cells in vivo. In wild-type C57BL/6 mice, there was a significant increase in mRNA for VCAM-1 in the retina 24 hours after intravitreous injection of $1 \mu \mathrm{g}$ VEGF as well as increases in mRNA for integrins $\beta_{1}$ and $\alpha_{4}$, which have been implicated in leukocyte adhesion to vascular endothelium, and an increase in mRNA for ICAM-2 48 hours after injection (Figure 8A); however, mRNA for ICAM-1 was not significantly increased between 12 and 48 hours after injection (Supplemental Figure 2D). Sustained expression of VEGF in doxycycline-treated Tet/opsin/VEGF mice resulted in significant increases in mRNA for VCAM-1, ICAM-2, integrin $\beta_{1}$, and integrin $\alpha_{4}$, which were first seen 3 days after onset of VEGF expression (Figure 8B), rather than after 1-2 days, as occurred after intravitreous injection of a large bolus of VEGF (Figure 8A). There was no increase in mRNA for ICAM-1, E selectin, P selectin, or VAP in the retinas of doxycycline-treated Tet/opsin/VEGF mice (Supplemental Figure 2, E-H).

Since the most dramatic and consistent VEGF-induced changes occurred in the mRNA for VCAM-1 and we also demonstrated an increase in VCAM-1 protein in cultured HRECs treated with VEGF, we investigated the effect of VEGF on VCAM-1 protein in retinal vessels in vivo. Twenty-four hours after intravitreous injection of PBS, there was little VCAM-1 in retinal vessels detectable by immunostaining (Figure 8, C-E), but 24 hours after injection of $1 \mu \mathrm{g}$ VEGF, there was strong staining for VCAM-1 in retinal vessels near the surface of the retina (Figure 8, F-H). Two approaches were used to assess the effect of VEGF on NF- $\mathrm{kB}$ transcriptional activity in vivo. First, a nonviral gene transfer approach that provides good transduction of retinal vascular endothelial cells (44) was used to transduce retinal cells with a NF- $\kappa \mathrm{B}$ reporter construct. Compared with intravitreous injection of PBS, injection of VEGF in mice with retinal transduction of the reporter construct caused significantly greater NF- $\mathrm{kB}$ transcriptional activity, as measured by dual-luciferase reporter assay (Figure 8I). 

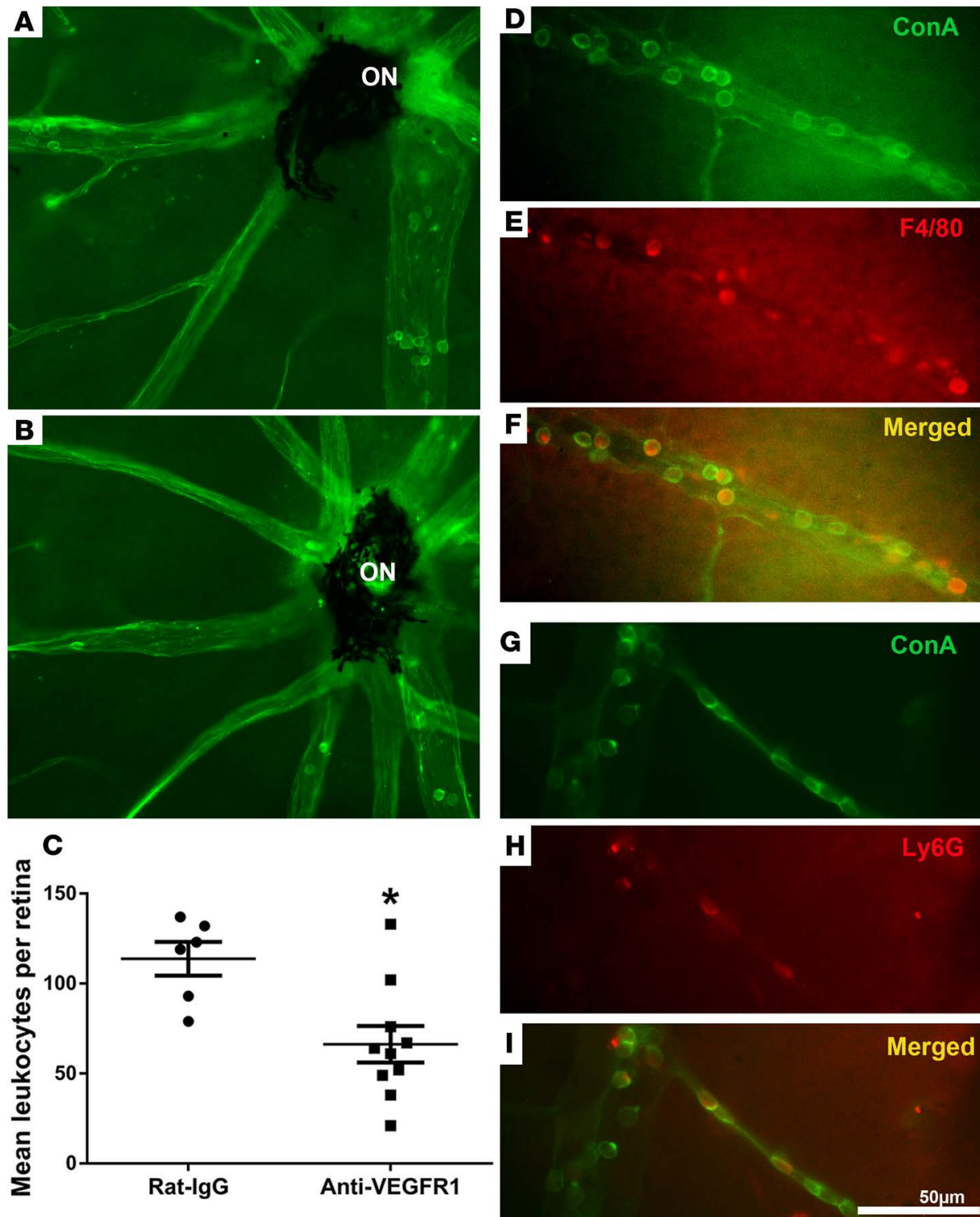
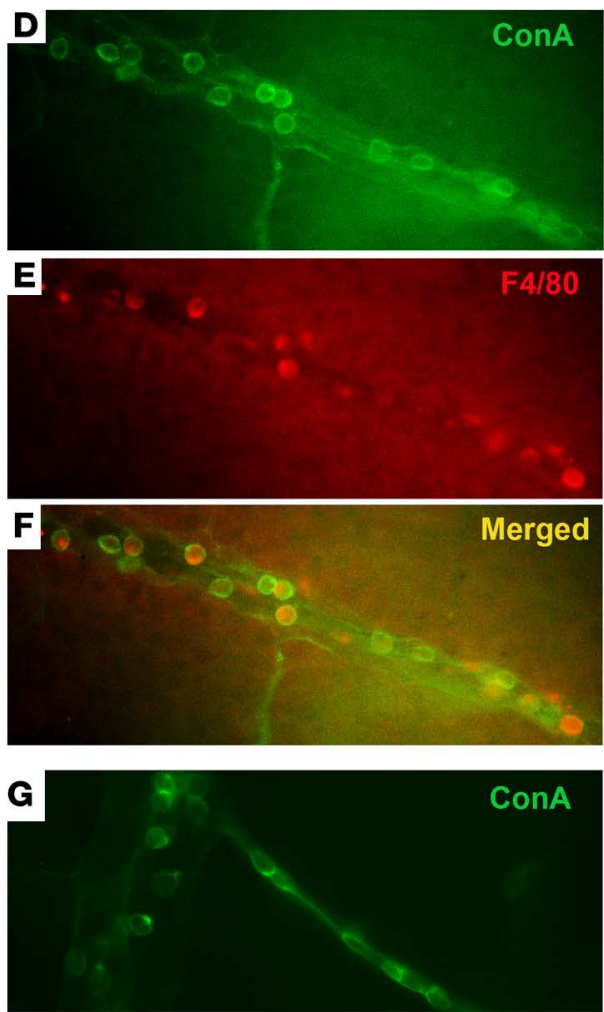

Figure 6. VEGFR1 contributes to leukocyte recruitment. $[57 \mathrm{BL} / 6$ mice were given a tail vein injection of $100 \mu \mathrm{g}$ rat anti-mouse VEGFR1 or rat IgG and then an intravitreous injection of 200 ng VEGF; 24 hours later, mice were perfused with FITC-labeled Con A. There were many intravascular leukocytes in rat IgG-injected mice $(\mathbf{A})$ and significantly fewer in those injected with anti-VEGFR1 (B and C) ( $n$ $=6$ for rat $\lg G$ and $n=10$ for anti-VEGFR1; ${ }^{*} P=$ 0.0069 for difference from rat lgG by unpaired $t$ test). Twenty-four hours after intravitreous injection of 200 ng VEGF, C57BL/6 mice were perfused with FITC-labeled Con A (green) and retinal flat mounts were counterstained (red) with anti-F4/80 (D-F) or anti-Ly6C (G-I). Scale bar: $50 \mu \mathrm{m}(\mathbf{D}-\mathbf{I})$.

Second, we investigated the effect of doxycycline-induced expression of VEGF in the retinas of Tet/opsin/VEGF mice on nuclear localization of NF-кB. Compared with nuclear fractions from retinal homogenates of untreated Tet/opsin/ $V E G F$ mice, those from mice treated with doxycycline for 1,2 , or 3 days showed higher levels of NF- $\mathrm{\kappa B}$ but equivalent levels of histone 3 (Figure 8J).

To determine the effect of blocking VCAM-1 on VEGF-induced retinal leukostasis Tet/opsin/VEGF mice were given an intravenous injection of $100 \mu \mathrm{g}$ rat antimouse VCAM-1 or rat IgG at the onset of doxycycline treatment. Three days after doxycycline treatment, were many intravascular leukocytes in the retinal vessels of rat IgG-treated mice (Figure 8K) and significantly fewer in those of anti-VCAM-1treated mice (Figure 8, $\mathrm{L}$ and $\mathrm{M}$ ).

\section{Discussion}

The treatment of DME, macular edema due to RVO, and neovascular age-related macular degeneration (AMD) has been revolutionized by the development of specific antagonists of VEGF. In addition, there has been an unexpected bonus, because neutralization of VEGF in the eyes of patients with ischemic retinopathies has shown that increased expression of VEGF in the retina does more than stimulate NV and excessive vascular leakage leading to macular edema, it also causes retinal hemorrhages, microaneurysms, and closure of retinal vessels (45). In this study, we have identified the mechanism by which high levels of VEGF cause retinal vessel closure; VEGF recruits leukocytes into retinal vessels and increases their adhesion to retinal vascular endothelial cells, resulting in vessel plugging and reduced perfusion. Activation of VEGFR1 on leukocytes contributes to their recruitment, because recruitment is reduced by systemic administration of an anti-VEGFR1 antibody. High levels of VEGF increase the transcriptional activity of $\mathrm{NF}-\mathrm{kB}$, which is a stimulator of expression of VCAM-1, other adhesion molecules, and cytokines that may further increase leukocyte recruitment and leukostasis. Neutralization of VCAM-1 with an anti-VCAM-1 antibody reduces VEGF-induced leukostasis.

These data provide important insights into the pathogenesis of RVO. Thrombosis of the central retinal vein or one of its branches disrupts venous return from the entire retina for the former and $25 \%-50 \%$ of the retina for the latter. Perfusion is compromised in the affected retina, resulting in retinal ischemia and 

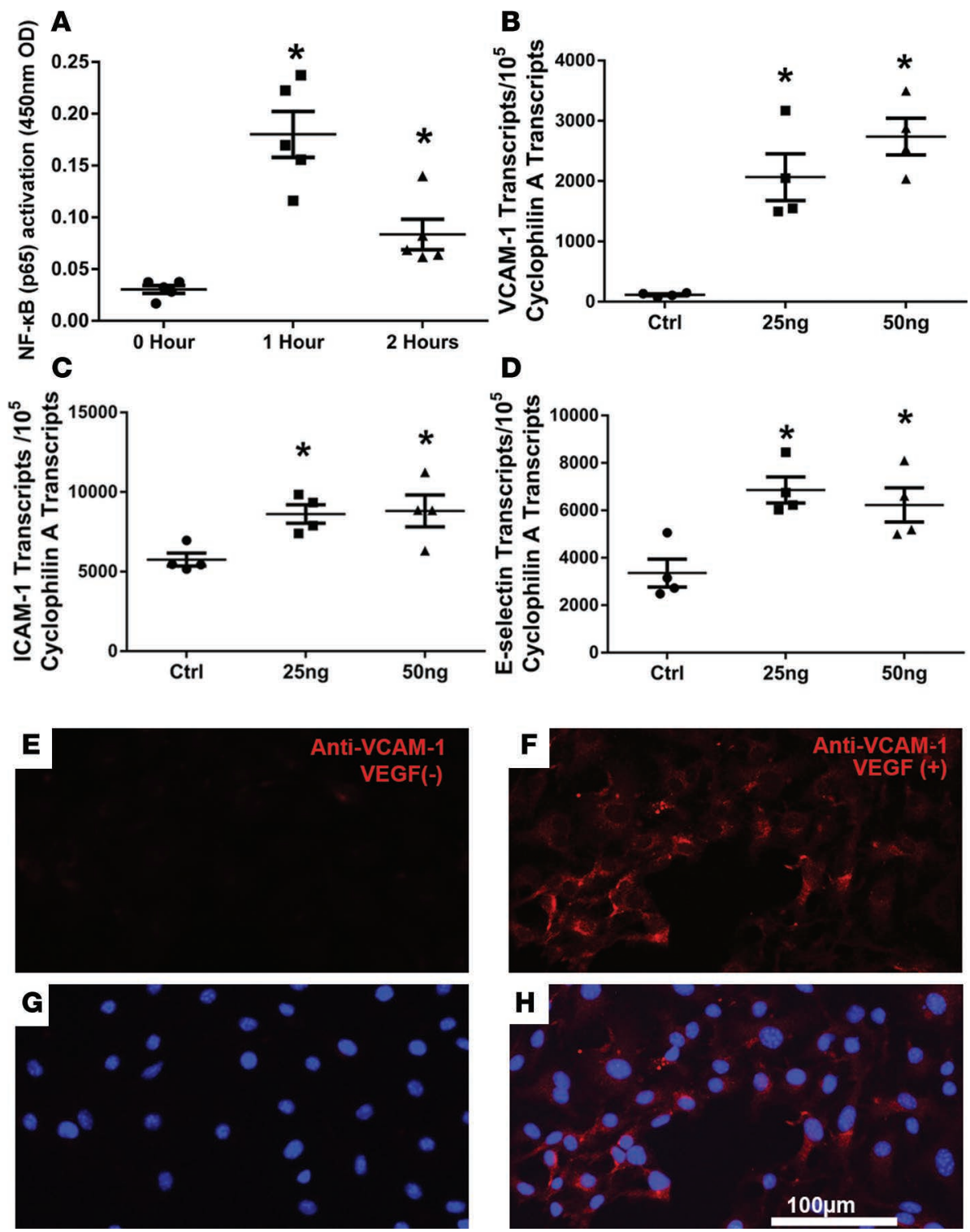

Figure 7. VEGF stimulates transcriptional activity of NF- $\kappa B$ and increases expression of adhesion molecules in retinal vascular endothelial cells. (A) Primary human retinal endothelial cells (HRECs) were incubated in $25 \mathrm{ng} / \mathrm{ml}$ VEGF for 0,1 , or 2 hours ( $n=5$ wells for each time point), and $3.5 \mu$ nuclear protein extract from each well was used to measure NF- $\kappa \mathrm{B}$ transcriptional activity, as described in Methods. Lines represent the mean ( \pm SEM) optical density (OD) at $450 \mathrm{~nm}$. ${ }^{*} P<0.001, P=0.032$ [2 hours] for comparison with unincubated controls by unpaired $t$ tests. (B-D) HRECs were incubated in 0, 25, or $50 \mathrm{ng} / \mathrm{ml}$ VEGF for 4 hours ( $n=4$ triplicate wells per group), and then mRNA for adhesion molecules was measured by qRT-PCR and normalized to mRNA for Cyclophilin $A$ for normalization. Lines represent mean ( \pm SEM) mRNA copies of target gene per $10^{5}$ copies of Cyclophilin A mRNA. ${ }^{*} P<0.05$ for comparison with unincubated controls by unpaired $t$ tests. (E-H) Primary mouse retinal endothelial cells were incubated in the absence (VEGF-) or presence of $25 \mathrm{ng} / \mathrm{ml} \mathrm{VEGF} \mathrm{for}$ 4 hours and then immunostained with rat anti-mouse VCAM-1 and goat anti-rat secondary antibody conjugated with Alexa Fluor 594 (red) and counterstained with Hoechst (blue); there was more VCAM-1 staining in VEGF-treated cells. Scale bar: $100 \mu \mathrm{m}$.

increased expression of VEGF. In some patients, particularly those that are older, there is immediate closure of some retinal capillaries and/or arterioles, probably due to preexistent arterial disease. Regardless of the amount of retinal vessel closure that occurs immediately after thrombosis, it is frequently followed by additional closure of retinal vessels that can be reversed by VEGF suppression (32-34). In untreated eyes with CRVO, the worsening of retinal nonperfusion can be so profound that it leads to severe loss of vision due to widespread ischemic death of retinal cells, including those in the macula and/or neovascular glaucoma, a severe complication that often leads to loss of the eye. This severe worsening of retinal nonperfusion was previously attributed to conversion from a nonischemic CRVO to an ischemic CRVO due to worsening of the vein occlusion, sometimes described as conversion of a partial CRVO to a complete CRVO $(46,47)$. However, measurement of area of retinal nonperfusion at several time points in RVO patients participating in clinical trials showed that progression of nonperfusion was the rule rather than the exception and that it did not occur abruptly, but rather progressed continuously through at least 24 months, the last measurement time point $(30,31)$. In these and other clinical trials $(32-34)$, it has been noted that subjects with substantial nonperfusion at baseline showed more rapid and often more severe worsening of nonperfusion than those with little or no nonperfusion at baseline. This suggests that all CRVOs are ischemic but to different degrees, resulting in different levels of VEGF expression, and it is eyes at the most severe end of the ischemia spectrum at baseline that tend to show the most rapid and extensive progression of retinal nonperfusion, which 
A

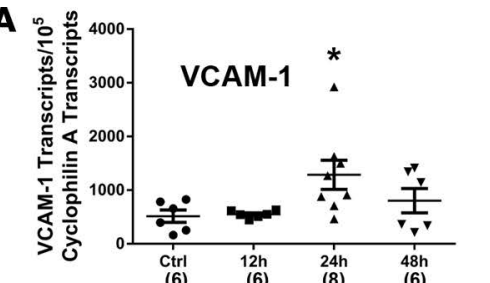

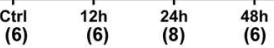

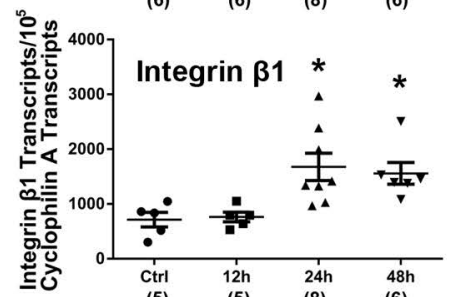

B

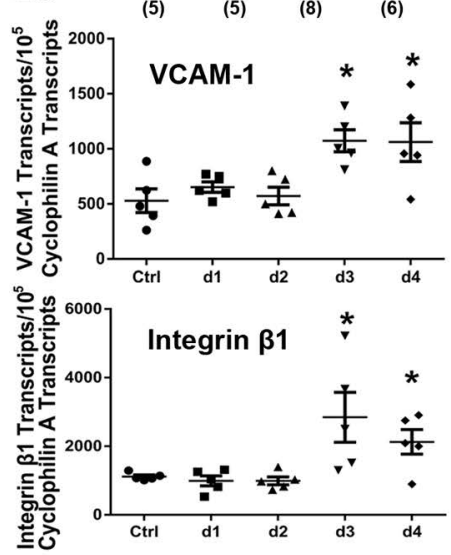

I
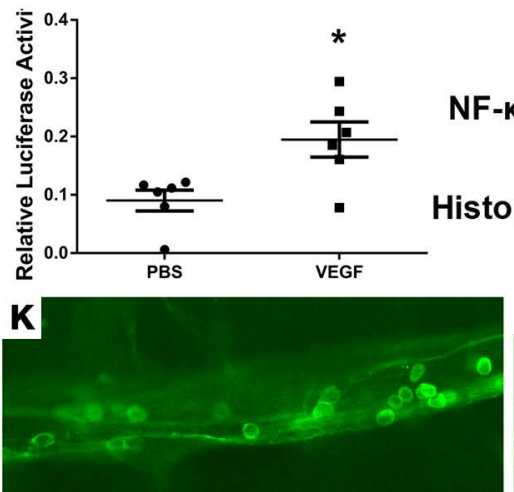
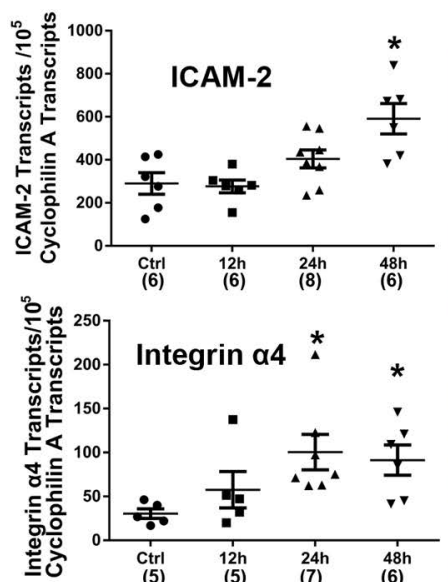

$\begin{array}{cccc}\text { Ctrl } & 12 \mathrm{~h} & 24 \mathrm{~h} & 48 \mathrm{~h} \\ (5) & (5) & (7) & (6)\end{array}$
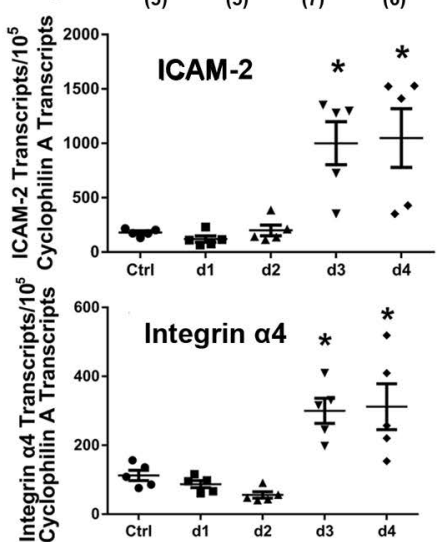

J

NF-KB

Histone 3

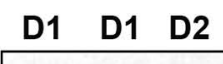

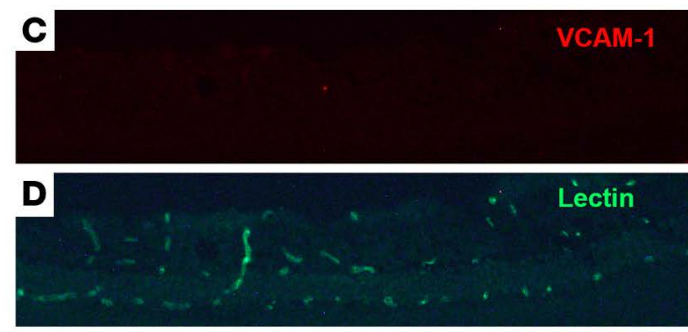
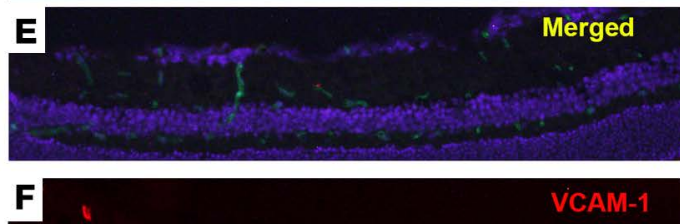

$\mathbf{F}$
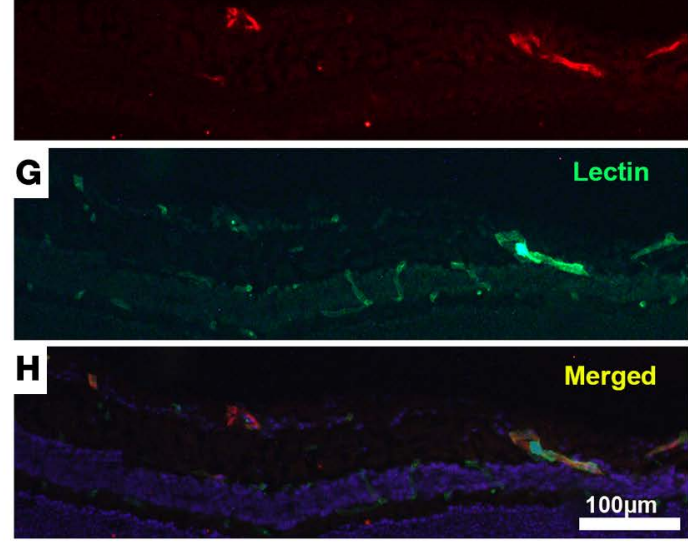

M

D3 Ctrl

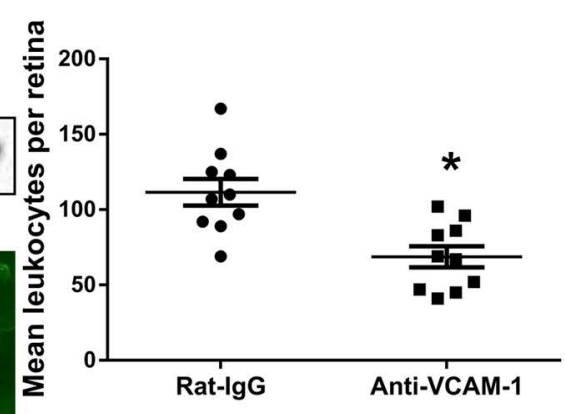

Figure 8. VEGF stimulates expression of VCAM-1 in the retina, and neutralization of VCAM-1 reduces VEGF-induced leukostasis. (A) C57BL/6 mice were given an intravitreous injection of PBS or $1 \mu \mathrm{g}$ VEGF, and qRT-PCR was used to measure retinal mRNA levels for several adhesion molecules. Compared with PBS controls, there was significant elevation of the mean ( $\pm \mathrm{SEM}$ ) number of mRNA transcripts per $10^{5}$ Cyclophilin $A$ transcripts for VCAM-1, ICAM-2, integrin $\beta 1$, and integrin $\alpha 4$ ( $n$ in parentheses along $x$ axis, ${ }^{*} P<0.05$ by unpaired $t$ tests). (B) In Tet/opsin/VEGF mice, the mean $\left( \pm\right.$ SEM) number of mRNA transcripts per $10^{5}$ Cyclophilin A transcripts for VCAM-1, ICAM-2, integrin $\beta 1$, and integrin $\alpha 4$ first became significantly elevated after 3 days of doxycycline treatment compared with controls not treated with doxycycline $\left(n=5{ }^{*} P<0.05\right.$ by unpaired $t$ tests $)$. (C-H) One day after C57BL/ 6 mice were given an intravitreous injection of $1 \mu \mathrm{g}$ VEGF in one eye and PBS in the fellow eye, ocular frozen sections immunostained for VCAM-1 (red) and Griffonia simplicifolia lectin (green) showed no detectable staining for VCAM-1 in PBS-injected eyes (C-E), but eyes that had been injected with VEGF showed several vessels that stained for VCAM-1 (F-H). (I) Fourteen days after subretinal injection of $0.5 \mu \mathrm{g}$ NF- $\mathrm{kB}$ luciferase reporter vector and $0.25 \mathrm{ng}$ Renilla luciferase plasmid in C57BL/6 mice, an intravitreous injection of $1 \mu \mathrm{g}$ VEGF was performed. Five days later, the ratio of Firefly/Renilla luciferase was measured in retinal/choroidal homogenates by Dual-Luciferase Reporter Assay. Lines show that the mean relative luciferase activity $(n=6)$ was significantly greater in VEGF-injected eyes compared with PBS-injected eyes ( ${ }^{*} P=0.0138$ by unpaired $t$ test). (J) Immunoblots of nuclear fractions from Tet/opsin/VEGF mice treated with doxycycline for 1 (D1), 2 (D2), or 3 days (D3) showed higher levels of NF- $\kappa B$ but equivalent histone 3 in nuclei from retinas with high levels of VEGF compared with those in untreated Tet/opsin/VEGF mice with low levels of VEGF (Ctrl). (K-M) Tet/opsin/VEGF mice ( $n=10$ for each group) were given an intravenous injection of $100 \mu \mathrm{g}$ anti-mouse VCAM-1 antibody or rat IgG; after 3 days of doxycycline treatment, there were many adherent leukocytes in retinal vessels of IgG-injected mice (K) and significantly fewer in eyes of anti-VCAM-1-injected mice ( $\mathbf{L}$ and $\mathbf{M})\left({ }^{*} P=0.0013\right.$ by unpaired $t$ test). Scale bar: $100 \mu \mathrm{m}$. 
occurs steadily, rather than as a sudden conversion. Since suppression of VEGF stops progression of nonperfusion and even causes reperfusion of some closed vessels, a causal role of high levels of VEGF has been established (32). The current study demonstrates the mechanism; high levels of VEGF in the retina stimulate recruitment and adhesion of leukocytes, resulting in plugging of large and small retinal vessels, and turning off VEGF expression or intraocular injection of a VEGF-neutralizing protein reduces leukostasis and allows closed vessels to reopen.

In early background diabetic retinopathy, there is not the sudden onset of retinal ischemia and high levels of VEGF that is seen in RVO, but there is evidence of small increases in retinal VEGF in experimental models of diabetes (48). The situation in RVO is mimicked by injecting a large bolus of VEGF into the vitreous or by doxycycline-induced expression of high levels of VEGF in Tet/opsin mice. In these models, there is severe leukostasis, resulting in plugging of large as well as small vessels over a relatively short time frame, as occurs in RVO. The situation in diabetic retinopathy is mimicked by rho/VEGF mice, in which there is a relatively small increase in VEGF, mild leukostasis that gradually increases, and, after several months, closure of retinal vessels occurs. Slowly progressing closure of retinal vessels is the underlying cause of progression of diabetic retinopathy (49), leading to substantial areas of ischemic retina, which further increases expression of VEGF and accelerates vessel closure and ischemia, which eventually reaches levels similar to those seen in RVO. Thus, while the time course is different, in both RVO and diabetic retinopathy increased expression of VEGF plays a major role in the progression of nonperfusion $(32,35)$, contributing to a positive feedback loop in which VEGF-induced leukostasis causes progressive closure of retinal vessels, increasing VEGF production, which worsens leukostasis and nonperfusion. This suggests that suppression of VEGF is not only important for treatment of macular edema and retinal NV, but is also necessary to halt progression of retinal nonperfusion and worsening of disease. Thus, normalization of VEGF levels should be the goal throughout the entire course of diabetic retinopathy and RVO; to achieve this, sustained delivery of VEGF antagonists or ocular gene transfer to express a VEGF-neutralizing protein is needed.

In addition to demonstrating the need for sustained suppression of VEGF throughout all stages of RVO and diabetic retinopathy, our study has identified additional potential therapeutic targets, VEGFR1 and VCAM-1. VEGFR1 is present on monocytes, macrophages, and neutrophils and mediates their migration along VEGF gradients in vitro and their recruitment into ischemic tissue in vivo $(42,43,50,51)$. Our data indicate that VEGFR1 contributes to leukocyte recruitment into the retinal vasculature when retinal levels of VEGF are high. Since blockade of VEGFR1 reduces leukocyte recruitment in the presence of elevated levels of VEGF, it may provide added benefit to VEGF-neutralizing agents, particularly in patients in whom neutralization of VEGF is incomplete and/or short lived. These data suggest that sustained delivery of a kinase inhibitor that blocks both VEGFR1 and VEGFR2 may have advantages over sustained delivery of a VEGF-binding agent for the long-term treatment of ischemic retinopathies.

High levels of VEGF increased NF- $\mathrm{kB}$ transcriptional activity in retinal endothelial cells and in the retina in vivo and increased the product of the NF- $\mathrm{kB}$-responsive gene Vcam1. Interestingly, expression of Vcam1 is increased to a greater extent than other NF- $\mathrm{kB}$-responsive genes in ischemic retina and is further increased much more than other $\mathrm{NF}-\kappa \mathrm{B}-$-responsive genes by exposure of ischemia retina to oxidative stress; its neutralization prevents exacerbation of ischemia-induced NV due to oxidative stress (52). Since neutralization of VCAM-1 reduces VEGF-induced leukostasis, it could provide added benefit to VEGF suppression in patients with ischemic retinopathies.

Leukostasis has previously been suggested to play a role in the pathogenesis of diabetic retinopathy. Mild leukocyte adhesion due to increased expression of ICAM-1 was observed within 3 days of the onset of hyperglycemia in rats with streptozotocin-induced diabetes and was associated with vascular leakage and endothelial cell death $(53,54)$. It was attenuated by aspirin, a COX-2 inhibitor, or suppression of TNF- $\alpha$ (55), and it was also reduced in diabetic mice deficient in CD18 or ICAM-1 (56). In hyperglycemic mice, the receptor for AGEs was implicated in upregulation of ICAM-1 and early leukocyte adhesion (57). This mild leukostasis is very different from the severe leukostasis described in the current study, and it is uncertain whether changes occurring within days of the onset of hyperglycemia play a role in vascular changes occurring many years later, but it is possible that mild leukostasis from hyperglycemia-induced upregulation of ICAM-1 could gradually lead to retinal ischemia and upregulation of VEGF that starts the positive feedback loop and progressive worsening of retinal nonperfusion described herein. 
The suggestion that sustained suppression of VEGF be considered for treatment of all stages of RVO and diabetic retinopathy may raise concerns with some clinicians and investigators because of the perception that prolonged suppression of VEGF could cause retinal damage. While macular atrophy has been observed in patients with neovascular AMD treated with injections of VEGF-neutralizing proteins, it also occurs as part of the natural history of AMD and has not been observed in patients with DME or RVO treated with prolonged suppression of VEGF. Conditional knockout of Vegf in RPE cells leads to loss of the choriocapillaris and retinal atrophy (58), but it is unlikely that complete elimination of intercellular VEGF signaling can be achieved without targeted gene disruption, and no retinal damage occurred in mice after transgenic expression of a potent VEGF-neutralizing protein for up to 7 months (59) or prolonged blockade of VEGFRs (60). If it were possible to cause retinal atrophy from suppression of VEGF, one would expect it to occur after subretinal injection of an AAV vector expressing a VEGF-binding protein, because RPE cells are strongly transduced by AAV vectors, but this was not observed (61).

In summary, this study demonstrates that high levels of VEGF in the retina recruit leukocytes into the retinal vasculature, at least in part, through stimulation of VEGFR1 and promote endothelial cell adhesion and vessel plugging through activation of NF- $\mathrm{KB}$ and increased expression of VCAM-1 as well as other adhesion molecules. This explains the clinical observation of reperfusion of previously nonperfused retinal vessels and reduced progression of nonperfusion in patients with ischemic retinopathies treated with intraocular injections of a VEGF-neutralizing protein. Our study also indicates that, despite different insults responsible for onset of retinal ischemia in RVO, diabetic retinopathy, and other ischemic retinopathies, they evolve into very similar diseases in which VEGF is the driver of an accelerating spiral of disease progression.

\section{Methods}

Mice. Wild-type C57BL/6 mice, Tet/opsin/VEGF double-transgenic mice (40), and rho/VEGF-transgenic mice (41) were treated in accordance with the Association for Research in Vision and Ophthalmology Guidelines on the care and use of animals in research. Adult C57BL/6 mice were anesthetized and given an intravitreous injection of 50,100, 200, 500, or 1,000 ng VEGF (R\&D Systems) or PBS. Adult Tet/opsin/ $V E G F$ mice had expression of VEGF induced by $2 \mathrm{mg} / \mathrm{ml}$ doxycycline in drinking water or daily intraperitoneal injections of doxycycline $(50 \mathrm{mg} / \mathrm{kg}$ on day $0,25 \mathrm{mg} / \mathrm{kg}$ on day 1 , and $25 \mathrm{mg} / \mathrm{kg}$ on day 2$)$. In some experiments, Tet/opsin/VEGF mice were given an intravitreous injection of $40 \mu \mathrm{g}$ aflibercept or PBS prior to doxycycline administration. Seven-month-old rho/VEGF mice were given subcutaneous injections of 25 $\mathrm{mg} / \mathrm{kg}$ aflibercept or PBS every other day for a total of 4 injections.

Measurement of retinal leukostasis. Leukostasis was measured as previously described (62). Briefly, mice were anesthetized and chests were opened to expose the heart; the right atrium was cut for drainage, a 27-gauge cannula was inserted into left ventricle, and the vasculature was flushed with PBS for 3 minutes for removal all nonadherent cells. Mice were then perfused over a span of 2-3 minutes with rhodamine- or FITC-labeled Con A (20 $\mu \mathrm{g} / \mathrm{ml}$ in PBS, $5 \mathrm{mg} / \mathrm{kg}$; Vector Labs, ThermoFisher). The vasculature was flushed for 4 minutes with PBS to remove residual unbound Con A. In some experiments, the vasculature was also perfused with fluorescein-labeled dextran (Sigma-Aldrich). Eyes were removed and fixed in 2\% PFA for 2 hours at room temperature, and retinas were dissected and flat mounted. Retinas were examined by fluorescence microscopy, and the number of intravascular leukocytes throughout the entire retina were counted by an investigator masked with respect to treatment group. To identify subtypes of adherent leukocytes, mice were perfused with FITC-labeled Con A and retinas were dissected, fixed, and permeabilized with 1\% Triton X-100 (Sigma-Aldrich) in PBS for 24 hours. Nonspecific binding was blocked by $1 \%$ bovine serum albumin (Sigma-Aldrich) in $5 \%$ horse serum (Invitrogen). After 3 washes with PBS, retinas were incubated with rat anti-mouse LyG6 (1:200; BioLegend) or rat anti-mouse F4/80 (1:200; BioLegend) overnight at $4^{\circ} \mathrm{C}$. After washing, retinas were incubated in Alexa Fluor 594-conjugated goat anti-rat secondary antibody (1:500; Invitrogen) for 1 hour at room temperature. Retinas were washed, flat mounted, and examined by fluorescence microscopy.

Assessment for retinal hypoxia. The Hypoxyprobe-RedAPC kit (Hypoxyprobe) was used to assess for retinal hypoxia. It utilizes pimonidazole, a 2-nitroimidazole, which is activated in hypoxic tissue and irreversibly binds thiol groups, and an Alexa Fluor 594-conjugated anti-pimonidazole antibody. Tet/opsin/VEGF mice were treated with doxycycline for 3 days and then given an intravitreous injection of $0.5 \mu 1$ of $500 \mu \mathrm{M}$ pimonidazole. After 90 minutes, mice were perfused with FITC-labeled Con A as described above. Eyes were removed, fixed in 2\% PFA for 2 hours, and stained with the anti-pimonidazole antibody. Retinas were flat mounted and examined by fluorescence microscopy. 
Fluorescein angiography. Mice had pupils dilated and were given a $50 \mu 1$ intraperitoneal injection of sodium fluorescein (AK-Fluor 10\%, Akorn), and fundus photographs were taken (Micro III Retinal Imaging Microscope, Phoenix Research Laboratories Inc.). For assessment of vascular perfusion, photographs were taken in the early recirculation phase 1 minute after fluorescein injection (63).

Quantitative RT-PCR. Retinas were dissected, immersed in $300 \mu \mathrm{T}$ Trizol, and roughly shaken for 2 minutes until completely solubilized. Total RNA was extracted with Direct-zol RNA Kits (Zymo Research) using centrifuge columns pretreated with DNAase to remove contaminating genomic DNA. The concentration of RNA suspended in RNAase-free water was measured with Nanodrops, and $1 \mu \mathrm{g}$ was reverse transcribed with Superscript III (Invitrogen). Primers specific for mouse VCAM-1, ICAM-1, ICAM-2, integrin $\beta 1$, integrin $\alpha 4$, VAP-1, E selectin, P selectin, and cyclophilin A (Supplemental Table 1) were added to cDNA and SYBR Green Supermix and run in an iCycler real-time PCR detection system (Bio-Rad). Standard curves were made for each molecule before quantification. Expression of each target gene was normalized to $10^{5}$ copies of cyclophilin A.

Effect of VEGF on NF- $\kappa B$ activation in vivo. Two approaches were used to assess the effect of VEGF on NF- $\kappa B$ transcriptional activity in vivo. First, a nonviral gene transfer approach that provides good transduction of retinal vascular endothelial cells (44) was used to express a NF- $\mathrm{BB}$ luciferase reporter vector (Affymatrix) in the retina. Briefly, mice were give a subretinal injection of $0.5 \mu \mathrm{g} \mathrm{NF- \kappa B}$ luciferase reporter vector together with $0.25 \mathrm{ng}$ Renilla luciferase plasmid (Promega) in $1 \mu 1 \mathrm{PBS}$. Fourteen days after subretinal injection, mice were given an intravitreous injection of $1 \mu \mathrm{g}$ VEGF or PBS for control. After 5 days, mice were euthanized; the retina and choroid from each eye were homogenized in $200 \mu 1$ reporter lysis buffer and centrifuged; and the supernatants were assayed in the Dual-Luciferase Reporter Assay (Promega). The mean Firefly/Renilla luciferase ratio is reported. The second approach was to measure the effect of VEGF on NF- $\mathrm{BB}$ nuclear translocation. Retinas were isolated from Tet/opsin/VEGF mice after 1, 2, or 3 days of doxycycline treatment or no doxycycline treatment. Nuclear fractions of retinal homogenates were isolated using a NE-PER Nuclear and Cytoplasmic Extraction Kit (ThermoFisher). Both retinas from each mouse were pooled and homogenized in $100 \mu \mathrm{C}$ CERI reagent, and after addition of $5.5 \mu 1 \mathrm{CERII}$ reagent, samples were centrifuged at $16,000 \mathrm{~g}$ for 15 minutes. Pellets were resuspended in $50 \mu 1$ NER reagent, and protein concentration was measured. Samples containing $15 \mu \mathrm{g}$ protein were resolved by $12 \% \mathrm{Nu}$-polyacrylamide gel electrophoresis (Invitrogen), transferred to polyvinylidene difluoride membrane (Invitrogen), and blocked with $5 \%$ BSA or $5 \%$ milk blocker buffer. The nuclear protein histone 3 was used as a control for loading, and due to the size difference between NF- $\mathrm{kB}(65 \mathrm{kD})$ and histone $3(17 \mathrm{kD})$, membranes were cut into a relatively high-molecular-weight portion that was incubated in rabbit anti-mouse NF- $\mathrm{BB}(1: 1,000$; Cell Signaling) in $5 \% \mathrm{BSA}$ at $4^{\circ} \mathrm{C}$ overnight and a relatively low-molecular-weight portion that was incubated in rabbit anti-mouse histone 3 (1:2,000; Cell Signaling) in 5\% BSA at $4^{\circ} \mathrm{C}$ overnight. After washing, membranes were incubated in goat anti-rabbit antibody (1:10,000 Invitrogen) and then SuperSignal West Dura Extended Duration Substrate (ThermoFisher). Blots were imaged and analyzed with a Bio-Rad imaging system.

Measurement of the effect of VEGF on NF- $\mathrm{KB}$ activation and target gene expression in cultured retinal endothelial cells. Primary HRECs (Cell Systems) and primary C57BL/6 mouse retinal microvascular endothelial cells (Cell Biologics) were cultured with basal medium (EBM) (Lonza) containing 10\% FBS and SingleQuots Kit supplements and growth factors (Lonza). The effect of VEGF on NF- $\kappa$ B transcriptional activity was measured as previously described (52). Briefly, HRECs were starved overnight in Opti-MEM (Life Technologies) and incubated in $25 \mathrm{ng} / \mathrm{ml}$ VEGF for 0,1 , or 2 hours ( $n=5$ wells for each time point). Cells were carefully removed with protein lysis buffer, nuclear protein extract was prepared from each well using the NE-PER Nuclear and Cytoplasmic Extraction Kit as described above, and protein concentration was determined using Bradford method (BioRad). Duplicate $3.5 \mu \mathrm{g}$ samples from each well were assayed

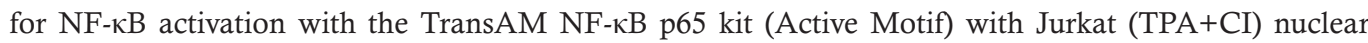
extract as positive control. To assess the effect of VEGF on NF- $\mathrm{BB}$ target gene expression, HRECs were starved overnight in Opti-MEM (Life Technologies), incubated in 25 or $50 \mathrm{ng} / \mathrm{ml}$ human VEGF for 4 hours, harvested, and total RNA was prepared for qRT-PCR to measure the mRNA for ICAM-1, VCAM1, ICAM-2, E selectin, P selectin, and VAP-1 as described above. HRECs were harvested and nuclear proteins were extracted with NE-PER Nuclear and Cytoplasmic Extraction Kit as above.

Immunofluorescent staining for VCAM-1. Mouse retinal microvascular endothelial cells were seeded on the chamber slide (Lab-Tek) and stimulated with $25 \mathrm{ng} / \mathrm{ml}$ VEGF for 4 hours after starvation overnight. Cells were fixed with $4 \%$ PFA, blocked with $5 \%$ horse serum, and incubated with (1:100) rat anti-mouse VCAM-1 
$(6 \mathrm{C} 7.1)(64,65)$ overnight at $4^{\circ} \mathrm{C}$ followed by incubation in goat anti-rat secondary antibody conjugated with Alexa Fluor 594 and Hoechst (Sigma-Aldrich). Cells were examined by fluorescence microscope.

Eyes were frozen in OCT and $10-\mu \mathrm{m}$ frozen ocular sections were fixed in 4\% PFA, blocked with 5\% horse serum in $0.05 \%$ PBST for 1 hour, and incubated overnight in 6C7.1 rat anti-mouse VCAM-1 and FITC-labeled Griffonia simplicifolia isolectin B4 (Vector Labs) that selectively stains vascular cells. Slides were rinsed with $0.05 \%$ PBST, blocked with $5 \%$ horse serum in $0.05 \%$ PBST for 25 minutes, and incubated in goat anti-rat secondary antibody conjugated with Alexa Fluor 594 and DAPI. Slides were examined by fluorescence microscopy.

Effect of neutralization of VEGFR1 or VCAM-1 on VEGF-induced leukostasis. Adult wild-type C57BL/6 mice were given an intravenous injection of $100 \mu \mathrm{g}$ anti-mouse VEGFR1 antibody ( $n=10$, MF-1, Eli Lilly) or rat IgG ( $n=6$, Sigma-Aldrich), and 24 hours later, 200 ng VEGF was injected into the vitreous cavity. The MF-1 anti-VEGFR1 clone has previously been demonstrated to bind VEGFR1 on leukocytes (66). After an additional 24 hours, mice were perfused with FITC-Con A, and the mean number of intravascular leukocytes per retina was measured as described above. Tet/opsin/VEGF mice were given an intravenous injection of $100 \mu \mathrm{g} 6 \mathrm{C} 7.1$ rat anti-mouse VCAM-1 antibody $(n=10)$ or rat IgG $(n=10)$ and $2 \mathrm{mg} / \mathrm{ml}$ doxycycline in drinking water. On day 3 of doxycycline treatment, mice were perfused with FITC-Con A, and the mean number of intravascular leukocytes per retina was measured.

Statistics. All statistical analyses were performed using Stata software, version 14.2 (StataCorp LP). Two-tailed Student's $t$ test was performed in experiments with a single experiment group compared with control group, while 1-way ANOVA was performed in comparisons among multiple experimental groups and control groups, followed by Bonferroni correction for multiple comparisons. A $P$ value of less than 0.05 was considered as statistically significant, and data are shown as mean \pm SEM.

Study approval. Protocols were approved by the Johns Hopkins Animal Care and Use Committee.

\section{Author contributions}

YL, JS, and PAC designed experiments; YL, JS, and SDF performed experiments; YL, JS, SDF, DV, and PAC troubleshot experiments; YL, JS, SDF, JW, DV, and PAC analyzed and interpreted data; JW performed statistical analyses; YL and PAC wrote the first draft of manuscript; YL, JS, SDF, JW, DV, and PAC edited the manuscript.

\section{Acknowledgments}

This work was supported by unrestricted grants from Andrew and Yvette Marriott, Per Bang-Jensen, and Jean Lake; funds from the Max Planck Society; and funds from DFG Excellence Cluster Cells in Motion (to DV).

Address correspondence to: Peter A. Campochiaro, The Wilmer Eye Institute, 815 Maumenee, The Johns Hopkins School of Medicine, 600 N. Wolfe Street, Baltimore, Maryland 21287-9277, USA. Phone: 410.955.5106; Email: pcampo@jhmi.edu.

YL's present address is: Department of Ophthalmology, Tianjin Medical University General Hospital, Tianjin, China.

1. Yau JW, et al. Global prevalence and major risk factors of diabetic retinopathy. Diabetes Care. 2012;35(3):556-564

2. Diabetes Control Complications Trial Research Group, et al. The effect of intensive treatment of diabetes on the development and progression of long-term complications in insulin-dependent diabetes mellitus. N Engl J Med. 1993;329(14):977-986.

3. [No authors listed]. Intensive blood-glucose control with sulphonylureas or insulin compared with conventional treatment and risk of complications in patients with type 2 diabetes (UKPDS 33). UK Prospective Diabetes Study (UKPDS) Group. Lancet. 1998;352(9131):837-853.

4. Klein R, Knudtson MD, Lee KE, Gangnon R, Klein BE. The Wisconsin Epidemiologic Study of Diabetic Retinopathy XXIII: the twenty-five-year incidence of macular edema in persons with type 1 diabetes. Ophthalmology. 2009;116(3):497-503.

5. Stitt AW. The role of advanced glycation in the pathogenesis of diabetic retinopathy. Exp Mol Pathol. 2003;75(1):95-108.

6. Kowluru RA, Kowluru V, Xiong Y, Ho YS. Overexpression of mitochondrial superoxide dismutase in mice protects the retina from diabetes-induced oxidative stress. Free Radic Biol Med. 2006;41(8):1191-1196.

7. Madsen-Bouterse SA, Kowluru RA. Oxidative stress and diabetic retinopathy: pathophysiological mechanisms and treatment perspectives. Rev Endocr Metab Disord. 2008;9(4):315-327.

8. Giacco F, Brownlee M. Oxidative stress and diabetic complications. Circ Res. 2010;107(9):1058-1070.

9. Joussen AM, et al. A central role for inflammation in the pathogenesis of diabetic retinopathy. FASEB J. 2004;18(12):1450-1452. 
10. Barber AJ, Lieth E, Khin SA, Antonetti DA, Buchanan AG, Gardner TW. Neural apoptosis in the retina during experimental and human diabetes. Early onset and effect of insulin. J Clin Invest. 1998;102(4):783-791.

11. Robinson R, Barathi VA, Chaurasia SS, Wong TY, Kern TS. Update on animal models of diabetic retinopathy: from molecular approaches to mice and higher mammals. Dis Model Mech. 2012;5(4):444-456.

12. Bresnick GH, De Venecia G, Myers FL, Harris JA, Davis MD. Retinal ischemia in diabetic retinopathy. Arch Ophthalmol. 1975;93(12):1300-1310.

13. Silva PS, et al. Diabetic retinopathy severity and peripheral lesions are associated with nonperfusion on ultrawide field angiography. Ophthalmology. 2015;122(12):2465-2472.

14. Klein R, Moss SE, Meuer SM, Klein BE. The 15-year cumulative incidence of retinal vein occlusion: the Beaver Dam Eye Study. Arch Ophthalmol. 2008;126(4):513-518.

15. Pournaras CJ, Tsacopoulos M, Strommer K, Gilodi N, Leuenberger PM. Experimental retinal branch vein occlusion in miniature pigs induces local tissue hypoxia and vasoproliferative microangiopathy. Ophthalmology. 1990;97(10):1321-1328.

16. Patz A, Eastham A, Higginbotham DH, Kleh T. Oxygen studies in retrolental fibroplasia. II. The production of the microscopic changes of retrolental fibroplasia in experimental animals. Am J Ophthalmol. 1953;36(11):1511-1522.

17. Smith LE, et al. Oxygen-induced retinopathy in the mouse. Invest Ophthalmol Vis Sci. 1994;35(1):101-111.

18. Aiello LP, et al. Suppression of retinal neovascularization in vivo by inhibition of vascular endothelial growth factor (VEGF) using soluble VEGF-receptor chimeric proteins. Proc Natl Acad Sci USA. 1995;92(23):10457-10461.

19. Adamis AP, et al. Inhibition of vascular endothelial growth factor prevents retinal ischemia-associated iris neovascularization in a nonhuman primate. Arch Ophthalmol. 1996;114(1):66-71.

20. Bakri SJ, Donaldson MJ, Link TP. Rapid regression of disc neovascularization in a patient with proliferative diabetic retinopathy following adjunctive intravitreal bevacizumab. Eye (Lond). 2006;20(12):1474-1475.

21. Writing Committee for the Diabetic Retinopathy Clinical Research Network, et al. Panretinal Photocoagulation vs Intravitreous Ranibizumab for Proliferative Diabetic Retinopathy: A Randomized Clinical Trial. JAMA. 2015;314(20):2137-2146.

22. Nguyen QD, Shah SM, Van Anden E, Sung JU, Vitale S, Campochiaro PA. Supplemental oxygen improves diabetic macular edema: a pilot study. Invest Ophthalmol Vis Sci. 2004;45(2):617-624.

23. Campochiaro PA, C99-PKC412-003 Study Group. Reduction of diabetic macular edema by oral administration of the kinase inhibitor PKC412. Invest Ophthalmol Vis Sci. 2004;45(3):922-931.

24. Nguyen QD, et al. Vascular endothelial growth factor is a critical stimulus for diabetic macular edema. Am J Ophthalmol. 2006;142(6):961-969.

25. Diabetic Retinopathy Clinical Research Network, et al. Randomized trial evaluating ranibizumab plus prompt or deferred laser or triamcinolone plus prompt laser for diabetic macular edema. Ophthalmology. 2010;117(6):1064-1077.e35.

26. Nguyen QD, et al. Ranibizumab for diabetic macular edema: results from 2 phase III randomized trials: RISE and RIDE. Ophthalmology. 2012;119(4):789-801.

27. Campochiaro PA, et al. Ranibizumab for macular edema due to retinal vein occlusions: implication of VEGF as a critical stimulator. Mol Ther. 2008;16(4):791-799.

28. Campochiaro PA, et al. Ranibizumab for macular edema following branch retinal vein occlusion: six-month primary end point results of a phase III study. Ophthalmology. 2010;117(6):1102-1112.e1.

29. Brown DM, et al. Ranibizumab for macular edema following central retinal vein occlusion: six-month primary end point results of a phase III study. Ophthalmology. 2010;117(6):1124-1133.e1.

30. Scott IU, et al. A randomized trial comparing the efficacy and safety of intravitreal triamcinolone with standard care to treat vision loss associated with macular edema secondary to branch retinal vein occlusion: the Standard Care vs Corticosteroid for Retinal Vein Occlusion (SCORE) study report 6. Arch Ophthalmol. 2009;127(9):1115-1128.

31. Ip MS, et al. A randomized trial comparing the efficacy and safety of intravitreal triamcinolone with observation to treat vision loss associated with macular edema secondary to central retinal vein occlusion: the Standard Care vs Corticosteroid for Retinal Vein Occlusion (SCORE) study report 5. Arch Ophthalmol. 2009;127(9):1101-1114.

32. Campochiaro PA, Bhisitkul RB, Shapiro H, Rubio RG. Vascular endothelial growth factor promotes progressive retinal nonperfusion in patients with retinal vein occlusion. Ophthalmology. 2013;120(4):795-802

33. Sophie R, et al. Long-term outcomes in ranibizumab-treated patients with retinal vein occlusion; the role of progression of retinal nonperfusion. Am J Ophthalmol. 2013;156(4):693-705.

34. Mir TA, et al. Changes in retinal nonperfusion associated with suppression of vascular endothelial growth factor in retinal vein occlusion. Ophthalmology. 2016;123(3):625-34.e1.

35. Campochiaro PA, Wykoff CC, Shapiro H, Rubio RG, Ehrlich JS. Neutralization of vascular endothelial growth factor slows progression of retinal nonperfusion in patients with diabetic macular edema. Ophthalmology. 2014;121(9):1783-1789.

36. Ip MS, Domalpally A, Hopkins JJ, Wong P, Ehrlich JS. Long-term effects of ranibizumab on diabetic retinopathy severity and progression. Arch Ophthalmol. 2012;130(9):1145-1152.

37. Papapetropoulos A, Garcia-Cardena G, Madri JA, Sessa WC. Nitric oxide production contributes to the angiogenic properties of vascular endothelial growht factor in human endothelial cells. J Clin Invest. 1997;100(12):3131-3139.

38. Kroll J, Waltenberger J. VEGF-A induces expression of eNOS and iNOS in endothelial cells via VEGF receptor-2 (KDR). BiochemBiophys Res Commun. 1998;252(3):743-746.

39. Walford G, Loscalzo J. Nitric oxide in vascular biology. J Thromb Haemost. 2003;1(10):2112-2118.

40. Ohno-Matsui K, et al. Inducible expression of vascular endothelial growth factor in adult mice causes severe proliferative retinopathy and retinal detachment. Am J Pathol. 2002;160(2):711-719.

41. Okamoto $\mathrm{N}$, et al. Transgenic mice with increased expression of vascular endothelial growth factor in the retina: a new model of intraretinal and subretinal neovascularization. Am J Pathol. 1997;151(1):281-291.

42. Barleon B, Sozzani S, Zhou D, Weich HA, Mantovani A, Marmé D. Migration of human monocytes in response to vascular endothelial growth factor (VEGF) is mediated via the VEGF receptor flt-1. Blood. 1996;87(8):3336-3343.

43. Massena S, et al. Identification and characterization of VEGF-A-responsive neutrophils expressing CD49d, VEGFR1, and CXCR4 in mice and humans. Blood. 2015;126(17):2016-2026. 
44. Kachi S, Esumi N, Zack DJ, Campochiaro PA. Sustained expression after nonviral ocular gene transfer using mammalian promoters. Gene Ther. 2006;13(9):798-804

45. Campochiaro PA, Aiello LP, Rosenfeld PJ. Anti-vascular endothelial growth factor agents in the treatment of retinal disease: from bench to bedside. Ophthalmology. 2016;123(10S):S78-S88.

46. Zegarra H, Gutman FA, Zakov N, Carim M. Partial occlusion of the central retinal vein. Am J Ophthalmol. 1983;96(3):330-337.

47. Arsene S, et al. Conversion from nonischemic to ischemic retinal vein occlusion: prediction by venous velocity on color Doppler imaging. Eur J Ophthalmol. 2009;19(6):1009-1016.

48. El-Remessy AB, Behzadian MA, Abou-Mohamed G, Franklin T, Caldwell RW, Caldwell RB. Experimental diabetes causes breakdown of the blood-retina barrier by a mechanism involving tyrosine nitration and increases in expression of vascular endothelial growth factor and urokinase plasminogen activator receptor. Am J Pathol. 2003;162(6):1995-2004.

49. Gardiner TA, Archer DB, Curtis TM, Stitt AW. Arteriolar involvement in the microvascular lesions of diabetic retinopathy: implications for pathogenesis. Microcirculation. 2007;14(1):25-38.

50. Clauss $\mathrm{M}$, et al. The vascular endothelial growth factor receptor Flt-1 mediates biological activities. Implications for a functional role of placenta growth factor in monocyte activation and chemotaxis. J Biol Chem. 1996;271(30):17629-17634.

51. Sawano A, et al. Flt-1, vascular endothelial growth factor receptor 1, is a novel cell surface marker for the lineage of monocyte-macrophages in humans. Blood. 2001;97(3):785-791.

52. Dong A, Shen J, Zeng M, Campochiaro PA. Vascular cell-adhesion molecule-1 plays a central role in the proangiogenic effects of oxidative stress. Proc Natl Acad Sci USA. 2011;108(35):14614-14619.

53. Miyamoto K, et al. Prevention of leukostasis and vascular leakage in streptozotocin-induced diabetic retinopathy via intercellular adhesion molecule-1 inhibition. Proc Natl Acad Sci USA. 1999;96(19):10836-10841.

54. Joussen AM, Murata T, Tsujikawa A, Kirchhof B, Bursell SE, Adamis AP. Leukocyte-mediated endothelial cell injury and death in the diabetic retina. Am J Pathol. 2001;158(1):147-152.

55. Joussen AM, et al. Nonsteroidal anti-inflammatory drugs prevent early diabetic retinopathy via TNF-alpha suppression. FASEB J. 2002;16(3):438-440.

56. Joussen AM, et al. A central role for inflammation in the pathogenesis of diabetic retinopathy. FASEB J. 2004;18(12):1450-1452.

57. Kaji Y, et al. Inhibition of diabetic leukostasis and blood-retinal barrier breakdown with a soluble form of a receptor for advanced glycation end products. Invest Ophthalmol Vis Sci. 2007;48(2):858-865.

58. Kurihara T, Westenskow PD, Bravo S, Aguilar E, Friedlander M. Targeted deletion of Vegfa in adult mice induces vision loss. J Clin Invest. 2012;122(11):4213-4217.

59. Ueno S, et al. Prolonged blockade of VEGF family members does not cause identifiable damage to retinal neurons or vessels. J Cell Physiol. 2008;217(1):13-22.

60. Miki A, et al. Prolonged blockade of VEGF receptors does not damage retinal photoreceptors or ganglion cells. J Cell Physiol. 2010;224(1):262-272.

61. Rakoczy EP, et al. Gene therapy with recombinant adeno-associated vectors for neovascular age-related macular degeneration: 1 year follow-up of a phase 1 randomised clinical trial. Lancet. 2015;386(10011):2395-2403.

62. Vinores SA, Xiao WH, Shen J, Campochiaro PA. TNF-alpha is critical for ischemia-induced leukostasis, but not retinal neovascularization nor VEGF-induced leakage. J Neuroimmunol. 2007;182(1-2):73-79.

63. Ehrenberg M, Ehrenberg S, Schwob O, Benny O. Murine fundus fluorescein angiography: An alternative approach using a handheld camera. Exp Eye Res. 2016;148:74-78.

64. Engelhardt B, Laschinger M, Schulz M, Samulowitz U, Vestweber D, Hoch G. The development of experimental autoimmune encephalomyelitis in the mouse requires alpha4-integrin but not alpha4beta7-integrin. J Clin Invest. 1998;102(12):2096-2105

65. Kim I, Moon SO, Kim SH, Kim HJ, Kou YS, Koh GY. Vascular endothelial growth factor expression of intercellular adhesion molecule 1 (ICAM-1), vascular cell adhesion molecule 1 (VCAM-1), and E-selectin through nuclear factor- $\mathrm{\kappa B}$ activation in endothelial cells. J Biol Chem. 2001;276(10):7614-7620.

66. Luttun A, et al. Revascularization of ischemic tissues by PlGF treatment, and inhibition of tumor angiogenesis, arthritis and atherosclerosis by anti-Flt1. Nat Med. 2002;8(8):831-839. 